\title{
Intracoronary optical coherence tomography: state of the art and future directions
}

Ziad A. Ali ${ }^{1,2 *}$, MD, DPhil; Keyvan Karimi Galougahi², MD, PhD; Gary S. Mintz², MD; Akiko Maehara ${ }^{2,3}$, MD; Richard A. Shlofmitz ${ }^{1}$, MD; Alessio Mattesini ${ }^{4}$, MD

1. DeMatteis Cardiovascular Institute, St. Francis Hospital \& Heart Center, Roslyn, NY, USA; 2. Clinical Trials Center, Cardiovascular Research Foundation, New York, NY, USA; 3. Center for Interventional Vascular Therapy, Division of Cardiology, NewYork-Presbyterian Hospital/Columbia University Irving Medical Center, New York, NY, USA; 4. Structural Interventional Cardiology Unit, Careggi University Hospital, Florence, Italy

This paper also includes supplementary data published online at: https://eurointervention.pcronline.com/doi/10.4244/EIJ-D-21-00089

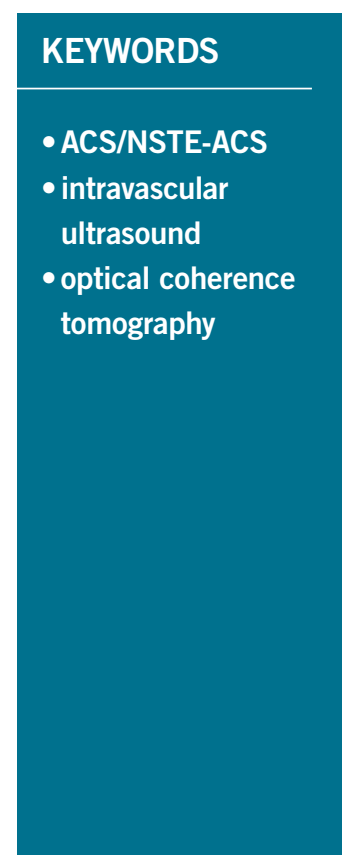

\section{Abstract}

Optical coherence tomography (OCT) has been increasingly utilised to guide percutaneous coronary intervention (PCI). Despite the diagnostic utility of OCT, facilitated by its high resolution, the impact of intracoronary OCT on clinical practice has thus far been limited. Difficulty in transitioning from intravascular ultrasound (IVUS), complex image interpretation, lack of a standardised algorithm for PCI guidance, and paucity of data from prospective clinical trials have contributed to the modest adoption. Herein, we provide a comprehensive up-do-date overview on the utility of OCT in coronary artery disease, including technical details, device set-up, simplified OCT image interpretation, recognition of the imaging artefacts, and an algorithmic approach for using OCT in PCI guidance. We discuss the utility of OCT in acute coronary syndromes, provide a summary of the clinical trial data, list the work in progress, and discuss the future directions.

*Corresponding author: St. Francis Hospital \& Heart Center 100 Port Washington Blvd., Roslyn, NY 11576, USA. 


\section{Abbreviations}

ACS acute coronary syndromes

BOOM bifurcation and ostial optical coherence tomography mapping

DES drug-eluting stents

IVUS intravascular ultrasound

MI myocardial infarction

MINOCA myocardial infarction with non-obstructive coronary arteries

MLA minimal lumen area

MLD MAX morphology, length, diameter, medial dissection, apposition, expansion

MSA minimal stent area

NSTEACS non-ST-segment elevation acute coronary syndromes

NURD non-uniform rotational distortion

OCT optical coherence tomography

OFR optical flow ratio

PCI percutaneous coronary intervention

STEMI ST-segment elevation myocardial infarction

TCFA thin-cap fibroatheroma

\section{Introduction}

Angiography, the cornerstone imaging modality in the cardiac catheterisation laboratory, has well-established limitations. These inherent limitations arise from angiography providing a lumenogram, depicting planar projections of the three-dimensional coronary tree, rather than imaging the vessel wall where the process of atherosclerosis manifests. Intravascular imaging - intravascular ultrasound (IVUS) and optical coherence tomography (OCT) - enables cross-sectional tomographic imaging of the coronary artery and provides additional information that is complementary to angiography. Intravascular imaging thus aids in the selection of treatment strategies and guidance of percutaneous coronary intervention (PCI). Registries ${ }^{1-3}$, randomised controlled trials ${ }^{4,5}$, and meta-analyses ${ }^{6,7}$ consistently support procedural and long-term benefits of intravascular imaging-guided PCI.

\section{OCT in PCI}

\section{INTRAVASCULAR OCT: TECHNOLOGY, ADVANTAGES,} LIMITATIONS, AND AVAILABLE IMAGING PLATFORMS

OCT utilises near-infrared light directed at the vessel wall through a rotating single optical fibre coupled with an imaging lens within a short-monorail imaging sheath. By measuring the amplitude and time delay of the backscattered light, OCT generates high-resolution, cross-sectional and three-dimensional volumetric images of the vessel microstructure. Due to the fast speed of light, interferometry is required for backscatter detection: this involves splitting the light into signal and reference beams, with the intensity of interference calculated according to the frequency differences between the two beams. Since blood strongly scatters light and attenuates the OCT signal, flushing is required to displace blood during OCT acquisition.

The shorter wavelength of the infrared light in OCT $(1.3 \mu \mathrm{m})$ compared with ultrasound in IVUS $(\sim 40 \mu \mathrm{m}$ at $40 \mathrm{MHz})$ confers greater axial resolution (10-20 $\mu \mathrm{m}$ versus $50-150 \mu \mathrm{m})$ but lower penetration depth (1-2 mm versus 5-6 mm), which limits OCT imaging, particularly in the presence of highly attenuating structures such as red thrombus or lipid/necrotic core.

Multiple intracoronary imaging OCT systems have been developed. Currently, the two systems most employed are the OPTISTM system (Abbott Vascular, Santa Clara, CA, USA), which also provides combined angiographic and OCT visualisation (co-registration), and the Lunawave ${ }^{\mathbb{R}}$ system (Terumo, Tokyo, Japan). Numerous other established companies and start-ups have released products or are in the process of entering the market, including Argus, Avinger, Canon, Conavi Medical, Dyad Medical, Forssman Medical, Gentuity, Horimed, InnerMedical, OCT Medical Incorporated, SpectraWave, and Vivolight, amongst several others. Novasight Hybrid ${ }^{\mathrm{TM}}$ (Conavi Medical Inc., Toronto, Canada) and Dual Sensor (Terumo) are the available OCT/IVUS hybrid catheter systems that are in use for research purposes, with the potential to provide the combined strengths of OCT and IVUS in a single catheter in clinical practice ${ }^{8}$.

\section{OCT IMAGE ACQUISITION: PRACTICAL STEPS}

Commercial OCT imaging systems consist of an OCT imaging catheter, a drive motor operating control, and imaging software. To set up OCT, the imaging catheter is attached to the purge syringe and flushed with the same material planned for coronary flushing (to maintain consistency in the index of refraction) and attached to the drive motor operating control. Intracoronary nitroglycerine is given before OCT imaging to eliminate spasm that may be caused by catheter irritation (Supplementary Figure 1). In order to achieve clearance during catheter pullback, it is critical to engage the guiding catheter at the coronary ostium. Deep-seating of the guide is unnecessary and may be counterproductive, as contrast injection may eject the guide, leading to suboptimal flushing. The subsequent imaging steps can be summarised as the four Ps: position, purge, puff, and pullback. The rapid exchange OCT catheter is advanced on the coronary guidewire and positioned distal to the target lesion ( $\sim 10 \mathrm{~mm}$ distally), the catheter is again purged, a small volume of flush is "puffed" through the guide catheter to evaluate clearance (if clarity is marginal, the engagement of the guide catheter with regard to the target vessel is checked and adjusted), and pullback is activated. In severely stenotic lesions where the OCT catheter may not cross the target lesion or the vessel clearance is expected to be poor, predilation should be performed. The contrast flush rate is set at $4 \mathrm{~mL} / \mathrm{sec}$ for a total volume of 14-16 mL for the left coronary artery and $3 \mathrm{~mL} / \mathrm{sec}$ for a total volume of $12-14 \mathrm{~mL}$ for the right coronary artery. If an automated injector is used, the pressure limit should be set at 300 psi or the nearest available. Contrast injection should stop immediately as the guide catheter is seen on the pullback to minimise contrast waste. Likewise, cine angiography should be performed during pullback to utilise contrast injection for angiography and for OCT co-registration if the feature is available. Although OCT acquisition, akin to any instrumentation in the coronary arteries, is not completely free of risk, nonetheless significant complications 
due to OCT acquisition are rare ${ }^{9}$ and can mostly be avoided by using meticulous techniques described in the present review.

\section{PCI GUIDANCE}

Pre-PCI assessment consists of quantitative and qualitative analysis. OCT can be used to identify the culprit lesion, assess lesion morphology to guide lesion preparation strategies ${ }^{10}$, and characterise the stent landing zones, thus allowing precise selection of the length and diameter of balloons and stents. As lack of a standardised algorithmic approach to OCT-guided PCI may be a factor in the limited adoption of the technology, procedural guidance during the PCI can be summarised with the mnemonic MLD MAX (morphology, length, diameter, medial dissection, apposition, expansion), fitting for the procedural goals of PCI.

\section{PRE-PCI GUIDANCE MORPHOLOGY}

Detailed assessment of normal and diseased morphology in coronary arteries by OCT is feasible by understanding the optical attenuation characteristics of vascular tissue layers. The trilaminar appearance represents the light scattering reflected from the layers of the normal vessel. Loss of this architecture generates appearances that correlate with different types of atherosclerotic lesion. A simplified algorithm for OCT image interpretation in native coronary arteries is shown in Figure 1. This algorithm is useful in describing the most frequent pathological morphologies in the vessel wall that include low-attenuating, signal-rich lesions (fibrous plaques), high-attenuating, signal-poor regions covered with fibrous cap (lipid-rich plaques), low-attenuating, sharply delineated, signal-poor regions (calcific plaques), and those inside the lumen, including the low-attenuating white thrombus and the high-attenuating red thrombus that casts a shadow on the vessel wall.

Assessment of lesion morphology on OCT can guide lesion preparation. Predilatation with an undersized balloon or a direct stenting approach may be appropriate in the presence of largely fibrous or lipid-rich plaques, whereas, in moderate or severely calcified lesions, non-compliant balloon predilation, use of a cutting or scoring balloon, atherectomy, or intravascular lithotripsy can be considered. In calcified lesions, IVUS delineates the calcification arc but not its thickness because of reflection of ultrasound waves off calcium (Figure 2). In contrast, OCT allows determination of both calcification arc and thickness in most cases. An OCT-based scoring system has been devised and validated in calcified lesions to help determine which calcific morphologies lead to stent underexpansion ${ }^{11,12}$. The factors identified may be easily recalled as the "rule of 5s": 1 point for maximum thickness $>0.5 \mathrm{~mm}, 1$ point for contiguous length of calcium $>5 \mathrm{~mm}$, and 1 point for maximum arc $>50 \%$ of the circumference of the vessel (i.e., $>180^{\circ}$ of the circumference). There was significantly lower stent expansion in target lesions with a total score of $\geq 3$ (all factors present), suggesting that calcium modification with atherectomy or intravascular lithotripsy may be needed, whereas stent expansion in lesions with scores of $\leq 2$ was generally acceptable. In the absence of adjunctive therapies for lesion preparation, calcium fracture using

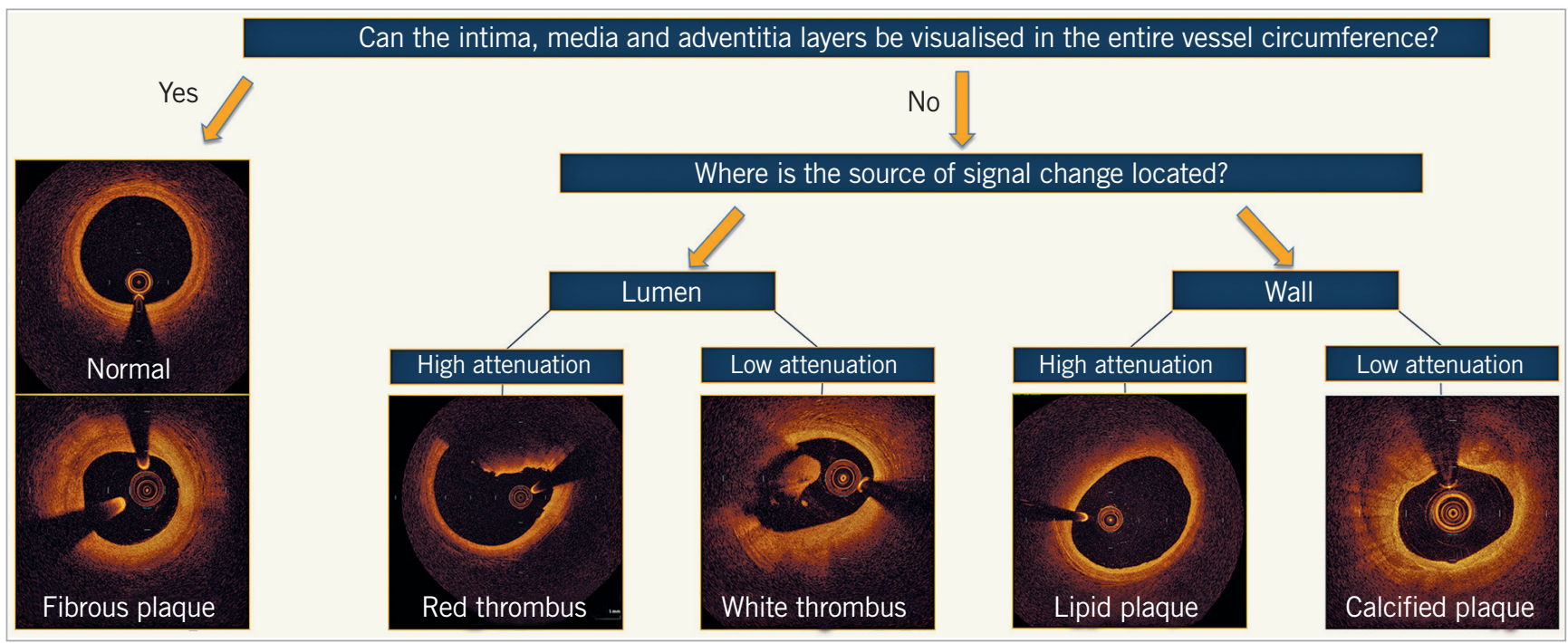

Figure 1. Algorithmic approach to optical coherence tomography image interpretation of common morphologies. The tri-laminar appearance of the normal vessel or fibrous plaque represents light scattering reflecting from the layers of the vessel without light attenuation. Hence, when the intima, media, and adventitia can be visualised for the entire vessel circumference, the cross-section represents either a normal segment or fibrous plaque; the latter of these can be differentiated by eccentric intimal thickening. The morphological characteristics of different plaque constituents exhibit different light attenuating properties. High attenuation occurs when there is complete absorbance of the near-infrared light, and low attenuation when the light is refracted, yet continues to allow visualisation of vessel characteristics towards the adventitia. When the source of the attenuation is in the lumen, high attenuation represents red thrombus and low attenuation represents white thrombus. When the source of the attenuation is in the vessel wall, high attenuation represents lipidic plaque, and low attenuation represents calcification. 


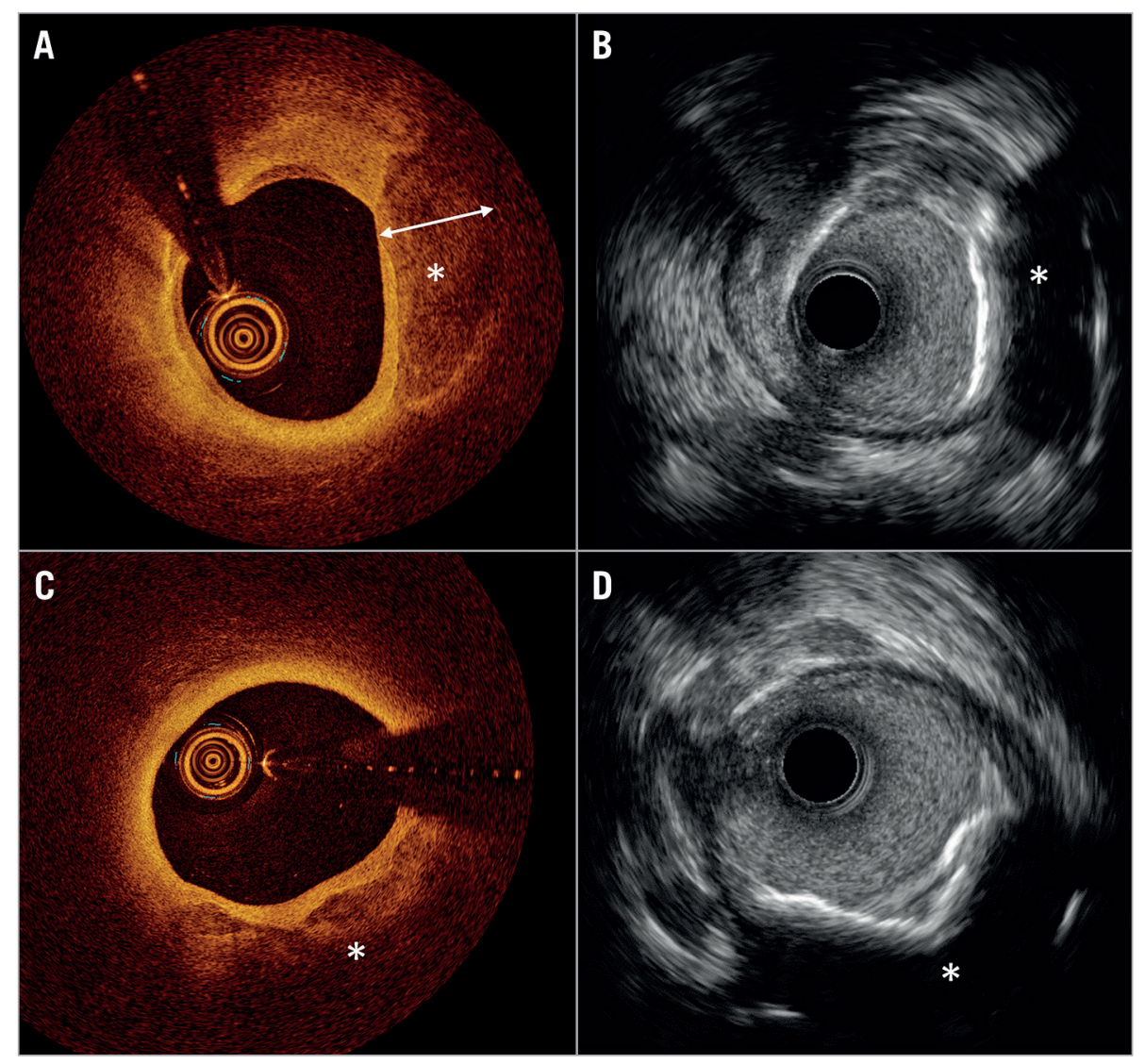

Figure 2. Comparison of coronary calcium imaging by optical coherence tomography and high-definition intravascular ultrasound. A) Optical coherence tomography (OCT) shows superficial calcium extending to the medial layer (*). The calcium (*), where thickness can be measured due to the optical properties of light penetration through the calcium crystal. B) Co-registered image on high-definition intravascular ultrasound (HD-IVUS) does not allow measurement of calcium thickness. C) OCT shows superficial calcium extending to the medial layer (*), where thickness cannot be measured due to the limited penetration depth of light. D) Co-registered image on HD-IVUS does not allow measurement of calcium thickness.

balloon angioplasty was best predicted by a calcium angle of $225^{\circ}$ and calcium thickness of $0.24 \mathrm{~mm}^{13}$. In the presence of a maximum calcium arc $>50 \%$ of the vessel circumference, lesions with calcium fracture have better stent expansion than those without ${ }^{13}$. Hence, the presence of calcium fracture, easily identified by OCT (Supplementary Figure 2), may be a goal for lesion preparation prior to stenting. Nevertheless, the relationship between calcium fracture on OCT and stent expansion warrants further assessment in appropriately designed prospective studies.

\section{LENGTH}

OCT software provides a two-dimensional lumenogram of the artery, incorporating multiplanar reconstruction of the threedimensional data, referred to as the lumen profile. Initially, the largest lumens proximal to the lesion and distal to the lesion on the lumen profile are used to create a region of interest. By scrolling through the OCT cross-sections at these sites, the most "normal" appearing segments within $5 \mathrm{~mm}$ are selected as proximal and distal reference frames (i.e., segments where there is minimal atherosclerotic plaque and hence greatest visibility of the arterial medial [external elastic lamina - EEL] and adventitial layers). The length of the lesion is then automatically calculated by the OCT software. Often, this number will not correspond to a commercially available drug-eluting stent (DES), so either the proximal or distal reference frame, whichever is in a more normal segment, is adjusted to an available DES length (Supplementary Figure 3). This approach minimises stent edge problems, including geographic miss and presence of thin-cap fibroatheroma (TCFA) at reference segments, which may lead to significant dissections and increase the risk of early stent thrombosis and post-PCI target lesion failure ${ }^{14-19}$.

\section{DIAMETER}

A step-by-step guide for measurement of vessel diameter and selection of stent diameter is provided in Figure 3. Briefly, an EEL-guided device sizing strategy is preferable to a lumen-guided strategy as it leads to the selection of a larger device size $(\approx 0.5 \mathrm{~mm})$ and consequently a larger lumen area without an increase in postprocedural complications ${ }^{20-22}$. EEL measurements may be utilised if two separate diameter measurements can be made in two different locations in the arterial wall that are at least one quadrant of the arterial circumference apart from each other. Greater than $180^{\circ}$ of EEL could be visualised in $\sim 80 \%$ of cases in the 


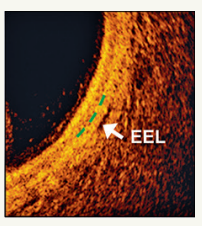

\section{PRE-PCI OCT}

\pm vessel preparation to visualise distal reference adequately if a severe stenosis interferes with distal clearance of blood or if initial OCT is suboptimal

\begin{tabular}{|l|l|}
\cline { 2 - 3 } \multicolumn{1}{c|}{} & $\begin{array}{c}\text { Can the EEL be identified at the } \\
\text { reference segments to allow } \\
2 \text { vessel diameter measurements } \\
\text { at least } 1 \text { quadrant apart? }\end{array}$ \\
\hline
\end{tabular}
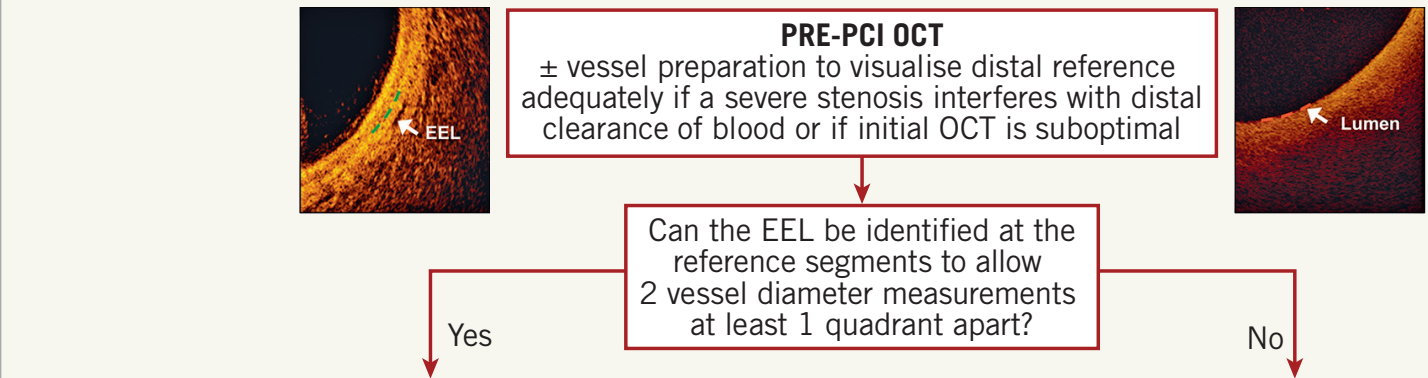

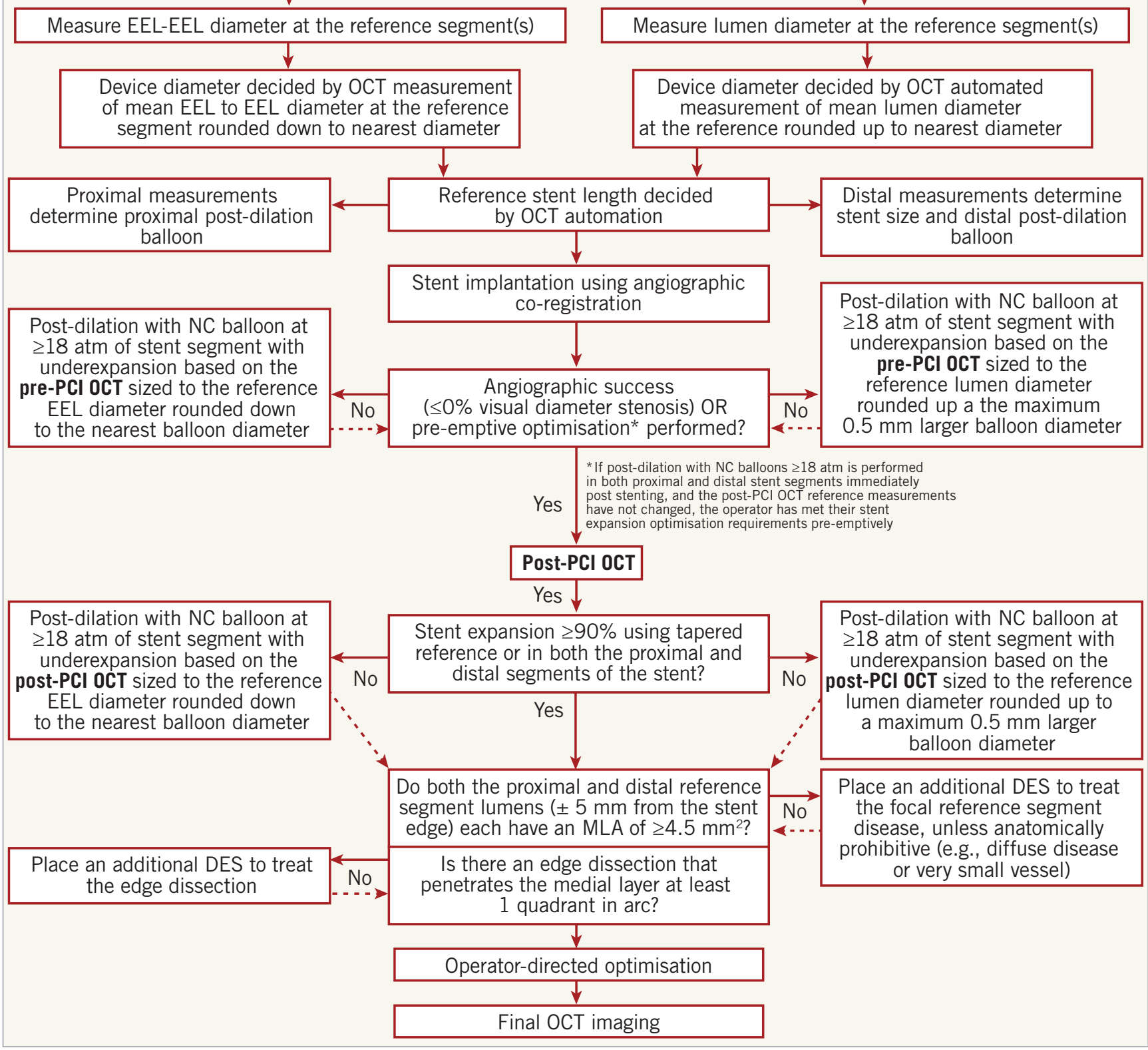

Figure 3. Optical coherence tomography-guided algorithm for percutaneous coronary intervention. Vessel diameter should be assessed using the external elastic lamina (EEL)-EEL diameter at the reference segments, and rounded down to select interventional devices (balloons, stents). If the EEL cannot be identified, luminal measures are used and rounded up to $0.5 \mathrm{~mm}$ larger for selection of the devices. Optical coherence tomography (OCT)-guided optimisation strategies post stent implantation per EEL-based diameter measurement and per lumenbased diameter measurement are shown. For instance, if the distal EEL-EEL diameter measures $3.2 \mathrm{~mm} \times 3.1 \mathrm{~mm}$ (i.e., the mean EEL-based diameter is $3.15 \mathrm{~mm}$ ), this number is rounded down to the next available stent size and post-dilation balloon to be used at the distal segment. Thus, a $3.0 \mathrm{~mm}$ stent and non-compliant balloon diameter is selected. If the proximal EEL cannot be visualised, the mean lumen diameter should be used for device sizing. For instance, if the mean proximal lumen diameter measures $3.4 \mathrm{~mm}$, this number is rounded up to the next available balloon diameter (within up to $0.5 \mathrm{~mm}$ larger) for post-dilation. MLA: minimal lumen area; MSA: minimal stent area; NC: non-compliant 
ILUMIEN III trial21 ${ }^{21}$ EEL-based measurements should be rounded down to determine the device size. If EEL visualisation is insufficient, the mean lumen diameter, recorded from the automated lumen profile feature, is utilised for device sizing. Lumen-based measurements should be rounded up, between 0.25 and $0.5 \mathrm{~mm}$, to determine the device size ${ }^{20}$. The distal measurements determine the stent size and post-dilation balloon size at the distal segment of the stent, and the proximal measurements determine the balloon size for post-dilation at the proximal segment of the stent.

\section{ANGIOGRAPHIC CO-REGISTRATION}

A software for automated real-time point-to-point correspondence between the coronary angiogram and OCT has been developed that reduces the errors in manual co-registration of angiography with OCT frames. The software presents the selected distal and proximal landing sites as markers on the co-registered angiography to guide precise stent implantation (Supplementary Figure 4), eliminating the perils of landing the stent edges in the angiographically normal appearing reference segments where plaque burden may be extensive ${ }^{23}$. In a randomised study, OCT-angiography co-registration aided in more precise stent deployment, eliminating large geographic miss ( $>5 \mathrm{~mm}$ ), and resulted in a trend towards reducing major stent edge dissection compared to angiography guidance ${ }^{24}$. Similar findings were reported in observational studies reporting geographic miss with a length of $\approx 5 \mathrm{~mm}$ with angiography guidance, stent coverage guided by angiography alone missing OCTidentified lesions in $70 \%$ of patients ${ }^{25}$, and changes in the device landing zone and stent length prompted by OCT co-registration in $\approx 20 \%$ of patients ${ }^{26,27}$. OCT-angiography co-registration can also aid in rapid identification and targeted post-dilation of underexpanded stent segments, thus avoiding unnecessary post-dilation, especially near the stent edges where post-dilation may result in edge dissection ${ }^{28}$. More recently, identification and mapping of the side branch ostium to minimise protrusion of stent struts into the main branch while ensuring full coverage of the ostium of the side branch, so-called bifurcation and ostial OCT mapping (BOOM), has been described ${ }^{29}$.

\section{POST-PCI GUIDANCE}

After stent deployment, the steps to assess the results, optimise stent deployment, and correct complications can be summarised with the mnemonic MAX.

\section{MEDIAL DISSECTION}

Reference segments are assessed on post-PCI OCT pullback to check for medial dissection and intramural haematoma (Supplementary Figure 5). The superior resolution of OCT has been criticised for providing "too much" information, identifying dissections in up to $40 \%$ of $\mathrm{PCI}^{21}$, of which $\approx 80 \%$ were not detectable by angiography, with no clinical impact ${ }^{30}$. Indeed, most dissections detected by OCT heal without consequence one year following $\mathrm{PCI}^{19,31}$. More recently, however, studies have confirmed the presence of major stent edge dissection detected by OCT as a predictor of poor outcomes ${ }^{15,16,18,19}$. In the CLI-OPCI registry, a linear rim of tissue with a width $>200$ $\mu \mathrm{m}$ was considered a major dissection and was associated with a 2.5-fold hazard of major adverse cardiac events (death, myocardial infarction $[\mathrm{MI}]$, target lesion revascularisation) at the distal edge but not at the proximal edge ${ }^{16,18}$. In a detailed analysis of OCTidentified edge dissections, van Zandvoort et $\mathrm{al}^{19}$ reported that cavity depth at the distal edge, reference lumen area at the proximal edge, and overall dissection length were predictors of the device-oriented composite endpoint (cardiac death, target lesion MI, target vessel revascularisation) at one year. In keeping with these findings, the ongoing ILUMIEN IV study categorises major dissections as those with medial dissection \pm intramural haematoma $\geq 60^{\circ}$ in arc from the centre of the vessel and $\geq 3 \mathrm{~mm}$ in length from the edge of the stent. Given the acquisition of a blinded OCT in the angiographic arm of ILUMIEN IV, detailed insights into edge dissections that are associated with target vessel failure will be gained from the trial. APPOSITION

Stent malapposition, recognised as an entity with the advent of intravascular imaging, refers to the lack of full contact between stent struts and the vessel wall following PCI. Malapposition may be present immediately after placement of stents (acute stent malapposition) or it may develop later (late stent malapposition), which can in turn be categorised as late persistent malapposition (ongoing since the time of implantation) or late acquired malapposition. Acute stent malapposition is a common finding after implantation of DES, observed on average in $15 \%$ of stents by IVUS ${ }^{32}$ and at a higher rate of $50 \%$ by $\mathrm{OCT}^{18}$ due to the higher resolution of OCT, flushing of the lumen, and the ability for automatic detection of the malapposed struts (Supplementary Figure 6). The potential impact of acute stent malapposition on stent failure rates (i.e., in-stent restenosis and stent thrombosis) has been a matter of controversy ${ }^{33}$. While bench-top in vitro experiments ${ }^{34}$, pathophysiological examination ${ }^{35}$, and small intravascular imaging studies $^{36}$ support a theoretical link between exposed, uncovered, malapposed struts and stent thrombosis, several larger intravascular imaging studies ${ }^{16,32,37,38}$ have shown no relationship between the presence and/or extent of acute stent malapposition and early, late, or very late stent thrombosis, or adverse events after DES implantation (Table 1) 15,16,18,32,37-42. While acute stent malapposition without underexpansion is not associated with increased stent failure rates, proximal edge malapposition that may interfere with re-wiring, gross malapposition for long segments (>3 mm), or malapposition associated with underexpansion may need correction. As the force required to oppose stent struts is different to that required to expand the struts, high-pressure inflation of non-compliant balloons may not be necessary, with low-pressure inflation of semicompliant balloons being sufficient.

\section{EXPANSION}

If the stent expands the lesion to diameters close to or equalling the diameter of the artery, the stent is considered adequately expanded (Supplementary Figure 7). The current European consensus is that a minimal stent area (MSA) $\geq 80 \%$ of the mean reference lumen area and/or $>4.5 \mathrm{~mm}^{2}$ on OCT is considered acceptable ${ }^{18,43}$. Nonetheless, multiple criteria for adequate expansion have been proposed and tested ${ }^{43}$, with the common goal of maximising the 
Table 1. Intravascular ultrasound and optical coherence tomography studies correlating stent malapposition with clinical outcomes.

\begin{tabular}{|c|c|c|c|c|c|c|c|}
\hline \multirow[b]{2}{*}{ Authors } & \multirow[b]{2}{*}{ Study } & \multirow{2}{*}{$\begin{array}{l}\text { Imaging } \\
\text { modality }\end{array}$} & \multirow{2}{*}{$\begin{array}{l}\text { Patients } \\
\text { (lesions) }\end{array}$} & \multirow{2}{*}{$\begin{array}{l}\text { Clinical } \\
\text { follow-up } \\
\text { (months) }\end{array}$} & \multicolumn{2}{|l|}{ Outcomes } & \multirow[b]{2}{*}{$p$-value } \\
\hline & & & & & Malapposition* & No malapposition & \\
\hline Van der Hoeven et al ${ }^{41}$ & MISSION & IVUS & 184 & 12 & $0 \% \mathrm{ST}$ & $0 \% \mathrm{ST}$ & NS \\
\hline Guo et $\mathrm{al}^{39}$ & HORIZONS-AMI & IVUS & $241(263)$ & 12 & $0 \%$ death or ST & $0 \%$ death or ST & NS \\
\hline \multirow[t]{2}{*}{ Steinberg et $\mathrm{al}^{37}$} & \multirow{2}{*}{$\begin{array}{l}\text { TAXUS IV, V, VI, } \\
\text { and ATLAS }\end{array}$} & \multirow[t]{2}{*}{ IVUS } & \multirow[t]{2}{*}{1,580} & 9 & $11.6 \%$ MACE & $8.8 \%$ MACE & 0.45 \\
\hline & & & & 24 & LASM: $8.3 \%$ MACE & 8.1\% MACE & 0.87 \\
\hline Wang et $\mathrm{al}^{32}$ & ADAPT-DES & IVUS & $2,072(2,446)$ & 24 & $5.2 \%$ MACE & $4.5 \%$ MACE & 0.58 \\
\hline Im et $a^{38}$ & & OCT & 351 (356) & 24 & $\begin{array}{l}\text { LPSM vs LASM vs LPSM and } \\
\text { LASM: } 2.2 \%, 3.2 \%, 0 \% \text { MACE }\end{array}$ & $3.2 \%$ MACE & 1.00 \\
\hline Soeda et $\mathrm{al}^{42}$ & MGH OCT registry & OCT & $786(900)$ & 12 & 1.7\% DoCE & 2.9\% DoCE & NS \\
\hline Prati et al ${ }^{18}$ & CLI-OPCI II & OCT & $832(1,002)$ & 12 & MACE HR: 1.15 (0.8-1.7) & & 0.52 \\
\hline Prati et al ${ }^{15}$ & CLI-OPCI ACS & OCT & $507(588)$ & 12 & MACE HR: $0.84(0.5-1.5)$ & & 0.57 \\
\hline Romagnoli et al ${ }^{40}$ & CLI-OPCI registry & OCT & $864(1,020)$ & 24 & MACE HR: 0.79 (0.5-1.2) & & 0.26 \\
\hline Prati et al ${ }^{16}$ & CLI-OPCI LATE & OCT & 1,211 & 36 & DoCE HR: 0.92 (0.7-1.2) & & 0.56 \\
\hline \multirow[t]{2}{*}{ Im et al ${ }^{115}$} & & \multirow[t]{2}{*}{ OCT } & \multirow[t]{2}{*}{351 (356) } & \multirow[t]{2}{*}{96} & LSM $7.3 \%$ MACE & $10.5 \%$ MACE & 0.82 \\
\hline & & & & & $\begin{array}{l}\text { LPSM vs LASM vs LPSM and } \\
\text { LASM: } 9.6 \%, 9.7 \%, 0 \% \text { MACE }\end{array}$ & $10.5 \%$ MACE & 0.47 \\
\hline
\end{tabular}

MSA, a consistent predictor of long-term PCI outcomes ${ }^{3,44-50}$. OCT software provide automatic measurement of stent diameter and expansion and detection of underexpanded segments. AptiVue ${ }^{\mathrm{TM}}$ Imaging Software, used with the OPTIS ${ }^{\text {TM }}$ Integrated System (both Abbott), provides two modes of expansion assessment: automatic comparison of the expansion to the closest respective proximal or distal reference in each half of the stented segment (dual reference mode) or automatic calculation of expansion based on an interpolation of the vessel size, considering OCT-detected side branches (tapered reference mode) (Supplementary Figure 7).

If stent underexpansion is identified on post-PCI OCT, the reference segments immediately outside the stent are used to re-measure the vessel size, preferentially by using EEL guidance, but lumen guidance is acceptable if the EEL is not visible (Figure 3 ). If the vessel size on post-PCI OCT has not changed compared with the measurements on pre-PCI OCT and the operator has pre-emptively post-dilated with a non-compliant balloon at $\geq 18$ atm, the requirements for minimal stent expansion optimisation may have been met; further optimisation is at the discretion of the operator. If the vessel size has changed such that a new balloon diameter is recommended, high-pressure post-dilatation ( $\geq 18 \mathrm{~atm}$ ) with non-compliant balloons sized to the target stent segment (EEL- or lumen-based according to the aforementioned algorithm for measurement) should be performed to match the optimisation criteria. If the subsequent OCT run shows persistent underexpansion, further optimisation for expansion is at the discretion of the operator. Both simple (higher inflation pressure, prolonged inflation) and advanced strategies (intravascular lithotripsy, excimer laser, the OPN ultra high-pressure balloon [SIS Medical, Frauenfeld, Switzerland]) for post-PCI optimisation may be considered when routine post-dilation is unsuccessful in improving stent expansion. Such optimisation should be performed considering that excimer laser with contrast injection (often required for stent optimisation in severely calcified lesions) and intravascular lithotripsy in implanted stents are "off-label" applications of these technologies. Overall, the potential benefit of further optimisation (e.g., in severe underexpansion) versus potential for harm (small incremental gain in expansion versus the risk of vessel perforation) needs to be carefully considered. While large studies of IVUS- versus angiography-guided PCI have shown that failure to meet the target expansion criteria is associated with worse outcomes ${ }^{5,45}$, whether not achieving the exact target optimisation criteria after performing the above steps is a reflection of inadequate optimisation or vessel anatomy and lesion characteristics is unclear.

Following OCT-guided optimisation of stent expansion, the proximal and distal reference segments, defined as the segments within $5 \mathrm{~mm}$ from the edges of the stent, are examined for inflow/ outflow disease. If both the proximal and distal reference segments have a minimal lumen area (MLA) $\geq 4.5 \mathrm{~mm}^{2}$, no further treatment is necessary. If there is untreated disease at the reference segment, defined as a focal MLA $<4.5 \mathrm{~mm}^{2}$ in either proximal or distal reference segments, additional DES should be implanted unless anatomically prohibitive (e.g., vessel tapering, distal diffuse disease, absence of a landing zone).

\section{OCT IMAGE ARTEFACTS AND LIMITATIONS}

For accurate OCT image interpretation, assessment of image quality and identifying artefacts are crucial. Some artefacts can be corrected with appropriate modifications to the imaging procedure. 
OCT artefacts can be categorised as artefacts that originate from light propagation in the catheter, lumen, or vessel wall, and artefacts related to catheter location and movement (Figure 4). Some lumen or vessel constituents strongly attenuate the OCT light, causing the appearance of shadows that reduce the intensity of the OCT signal in the arterial wall. Inadequate blood clearance generates signal-rich areas within the lumen, causing interference that decreases the intensity of the OCT signal from the arterial wall (Figure 4A, Figure 4B). In addition, blood swirling, particularly at the beginning or end of a pullback, can be mistaken for thrombus or plaque erosion (Figure 4C, Figure 4D). Red thrombus attenuates the OCT light, while metallic stent struts and guidewires block incident OCT light, casting shadows on the vessel wall.

The catheter location within the vessel lumen and the vessel diameter can affect the OCT image. The catheter may prolapse on itself if undue force is used (Figure 4E). Additionally, movement of the imaging catheter, due to rotation and pullback speed, can alter the OCT image appearance. Non-uniform rotational distortion (NURD) is due to non-constant angular velocity of the monofibre optical catheter and appears as a blurring or smearing in the lateral direction. NURD occurs due to rotational resistance in the catheter due to a tortuous or narrow vessel, a tight haemostatic valve, or a crimped catheter sheath (Figure 4F, Figure 4G). When the imaging catheter is positioned close to the arterial wall such that the light is emitted parallel to the tissue surface, that part of the arterial wall may appear to attenuate the light when in reality the optical beam is not penetrating that region. This artefact may be confused with the appearance of TCFA, superficial accumulation of macrophages, lipid pool, or necrotic core (Figure 4H).

OCT has some recognised limitations. OCT performs poorly in assessing the aorto-ostial coronary segments. This weakness is due to difficulty in obtaining optimal blood clearance at the coronary ostia. Using techniques such as gentle withdrawal of the guiding catheter during contrast injection, while useful, does not always result in adequate clearance and acceptable image quality in coronary ostia. Some authors have reported their experience with OCT for PCI guidance in the left main coronary artery, which is feasible for lesions located at the mid segment and distal left main bifurcation but remains challenging at the ostium even in highly experienced hands ${ }^{51}$.

\section{OCT: ACUTE CORONARY SYNDROMES}

The high resolution of OCT enables identification of the details relevant to PCI strategy in acute coronary syndromes (ACS), such as plaque rupture, erosion, thrombotic debris, dissection, calcified nodules, calcium requiring lesion preparation, and TCFA ${ }^{52,53}$. This section will focus on morphological considerations in ACS.

The most common underlying culprit lesion for ACS in patients with obstructive atherosclerotic coronary disease is a ruptured lipid-rich plaque ${ }^{54,55}$. On OCT, ruptured plaque is identified by the presence of discontinuity in the fibrous cap that is associated with a cavity inside a lipid-rich plaque (Figure 5A-Figure 5E). Overhanging thrombotic material is often visualised in patients

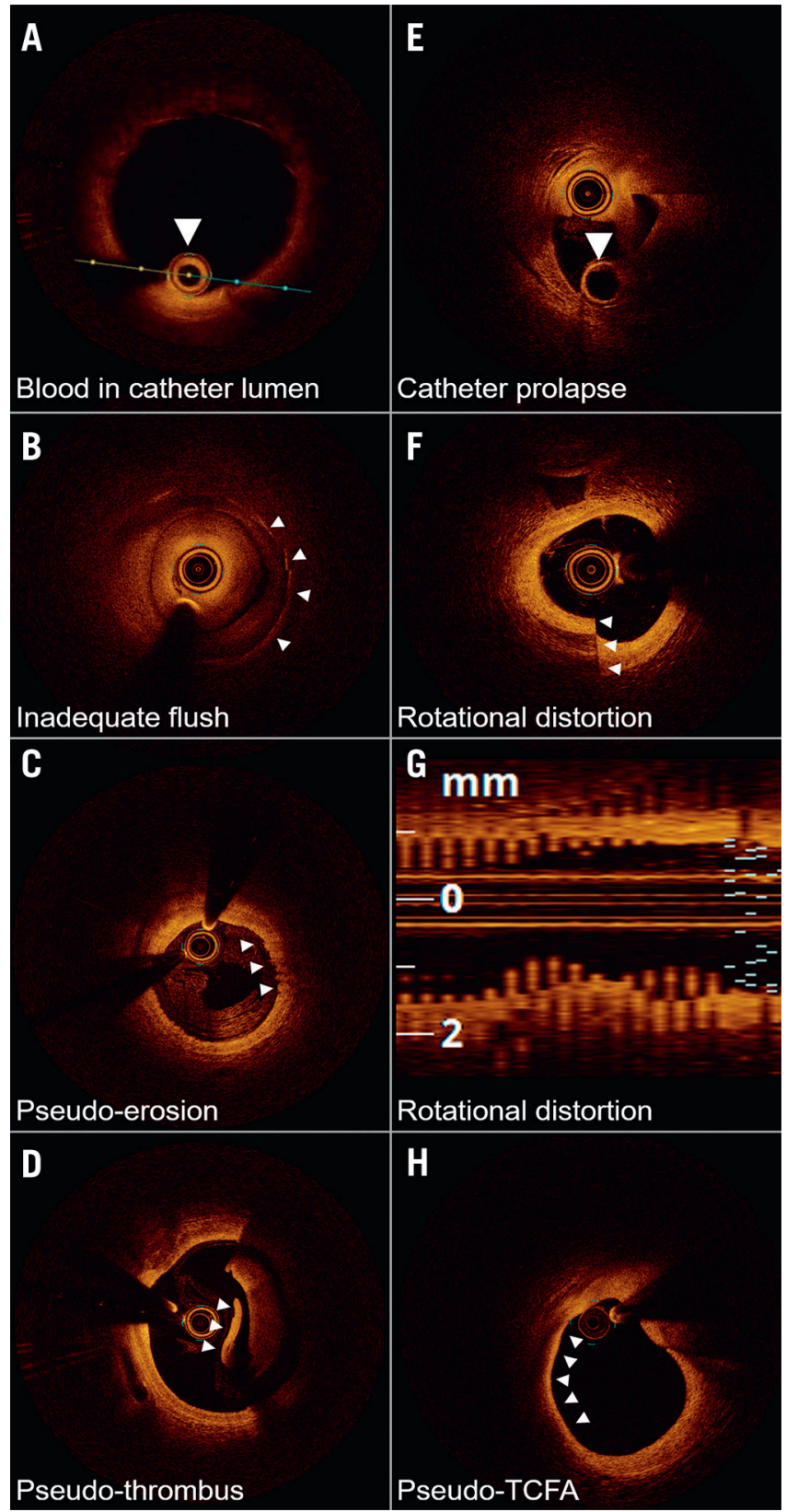

Figure 4. Optical coherence tomography imaging artefacts. A) Blood accumulation within the catheter (arrow) attenuates the nearinfrared light transmission, obscuring the image. B) Poor flush, often occurring at the beginning or end of the optical coherence tomography (OCT) image acquisition, mimics the appearance of neointimal hyperplasia over the stent struts (arrows). C) Haematic components within flush media refract light, creating an artefactual appearance of an erosion (arrows). D) Poor flush clearance of blood gives the appearance of red thrombus. Layering pattern (arrowhead) suggests artefact. E) The OCT catheter is folded on itself, with imaging lens prolapsed over the empty rapid exchange port (arrow). F) Non-uniform rotational distortion demonstrating a split appearance, confirmed on the $(G)$ longitudinal image demonstrating the classic saw-tooth pattern. H) Thin-cap fibroatheroma (TCFA) artefact is most commonly seen at bends in the artery wall or in large vessels where the distance required for the light to travel and poor tissue penetration generate the false appearances. 


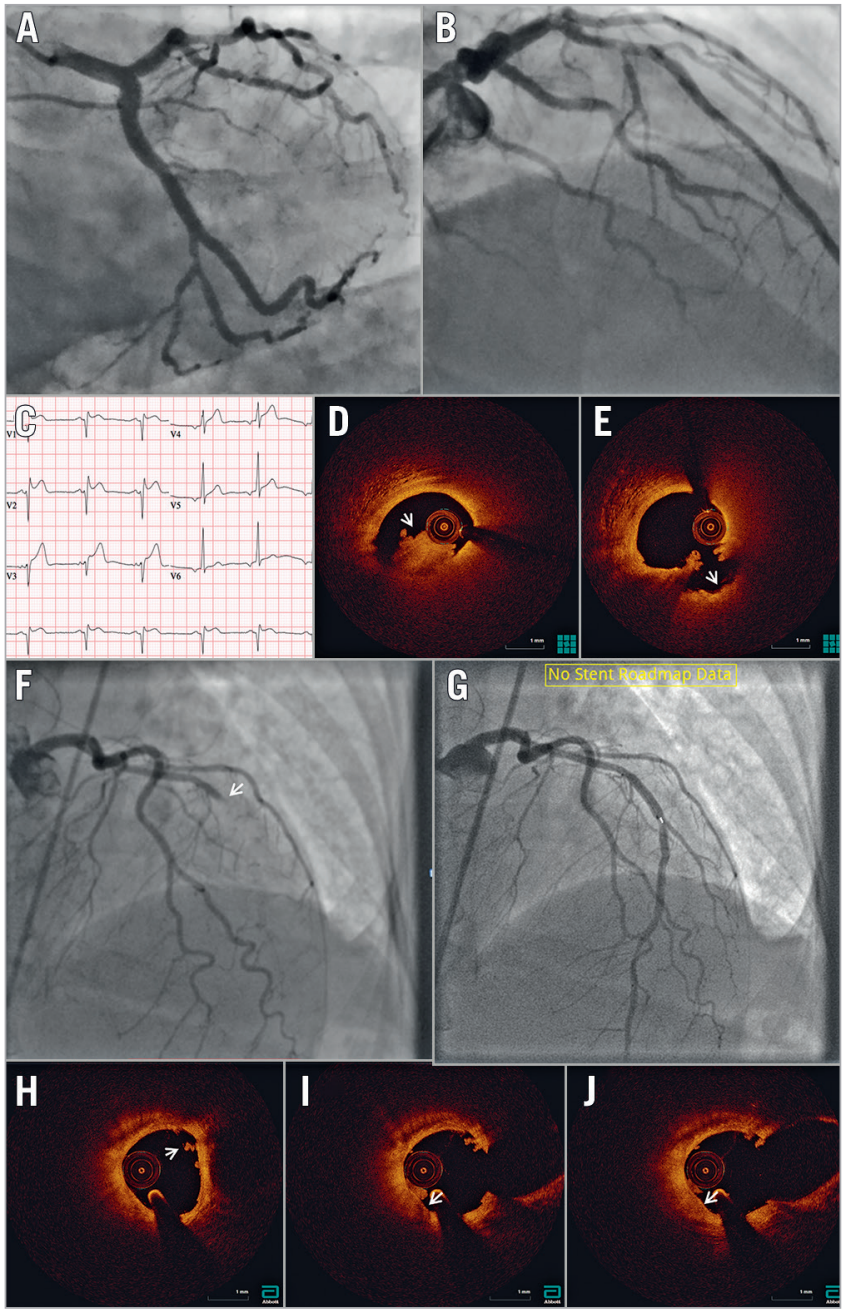

Figure 5. OCT in ST-segment elevation myocardial infarction. A) \& B) Angiography does not identify a clear culprit lesion. C) Based on ST-segment elevation in the anterior leads, suggesting myocardial infarction with non-obstructive coronary arteries (MINOCA), optical coherence tomography (OCT) was performed in the left anterior descending coronary (LAD) artery, identifying (D) red thrombus (arrowhead) just proximal to the dominant septal. Following aspiration (E), repeat OCT shows the typical appearance of a crater with a smooth inner surface (arrowhead). F) Angiography identifies an occlusion at the mid-LAD segment (arrowhead). G) Following aspiration, repeat OCT with angiographic co-registration identifies (H) white thrombus (arrowhead) with no underlying plaque rupture. I) \& J) Notably, white thrombus is adherent to a high attenuation thin-cap fibroatheroma (arrowhead), suggesting the possibility of erosion as the mechanism of MINOCA. The patient was started on dual antiplatelet therapy and the stent was not placed.

presenting acutely, but its presence is not mandatory for diagnosis since the early use of antithrombotic and antiplatelet drugs may dissolve the thrombus before coronary catheterisation is performed or thrombi may be mechanically removed if aspiration thrombectomy is performed. Although plaque rupture is the most frequent finding in ACS, pathologic studies have demonstrated the presence of plaque erosion in about $20-30 \%$ of patients (Figure 5F-Figure 5J) ${ }^{56}$. The ability to differentiate between plaque rupture and erosion is potentially helpful in guiding treatment strategies, perhaps with deferral of stenting in non-critical stenoses with plaque erosion (Figure 6) ${ }^{57}$, although randomised data are warranted before this approach can be broadly recommended.

The pivotal histopathological criterion to identify plaque erosion is the absence of endothelial lining over the underlying plaque. Despite its high spatial resolution, OCT is unable to evaluate the presence of endothelial disruption ${ }^{58}$. Diagnosis of plaque erosion on OCT is, therefore, based mainly on the exclusion of ruptured fibrous cap ${ }^{56}$. The most frequent subtle changes observed on OCT in plaque erosion are: (a) white thrombus on an intact fibrous cap, (b) no thrombus but presence of an irregular lumen surface, or (c) thrombus attenuating the underlying plaque in the absence of lipidic plaque or calcification immediately proximal or distal to the site of thrombus (Supplementary Figure 8). Plaque erosion may be defined as "definite" when there is visualised thrombus on an intact fibrous cap or "probable" in the absence of rupture or thrombus but with luminal irregularity present.

Calcified nodules are the least common cause of ACS. Both pathologic ${ }^{55}$ and imaging studies ${ }^{59}$ have confirmed the existence of calcified nodules and their clinical impact ${ }^{56,60}$. Recently, Sugiyama at $a l^{60}$ conducted a detailed analysis of calcified plaques on OCT in patients with ACS to study the prevalence of different morphologies of calcific plaques at the culprit lesion site. Calcification at the site of the culprit lesion was found in 157 out of 1,241 (12.7\%) patients presenting with ACS in whom OCT assessment was undertaken prior to intervention. The authors identified three different plaque types at the site of culprit lesions (Supplementary Figure 9), namely eruptive calcified nodules, superficial calcific sheet, and calcified protrusion (with a prevalence of $25.5 \%$, $67.4 \%$, and $7.1 \%$, respectively $)^{60}$. Of these calcific plaque subtypes, eruptive calcified nodules are shown to be responsible for ACS in histopathologic studies, whereas calcific sheet and calcified protrusion are a part of the underlying fibroatheroma and are not shown to be the cause of ACS. Indeed, a recent study by Prati et $\mathrm{al}^{61}$ showed that calcified nodules with disruption of the fibrous cap versus those without were associated with an $\approx 6.5$ fold higher risk of cardiac mortality. Nonetheless, all three calcific plaque types were associated with more periprocedural complications and suboptimal PCI results compared with non-calcified culprit plaques (Figure 7) ${ }^{60}$. Eruptive calcified nodules were frequently located in the right coronary artery (44.4\%), whereas superficial calcific sheets were most frequently found in the left anterior descending artery $(68.4 \%)^{60}$. The exact biology leading to the different types of calcified nodules remains controversial. One current hypothesis is that mechanical stress could fragment sheets of calcium, resulting in small nodules that are surrounded by fibrin that may eventually erupt through the plaque surface. Eruptive calcified nodules are frequently located in the mid right coronary artery where cyclic hinge movement may cause weakening of calcified plaques leading to fracture ${ }^{60,62}$. 


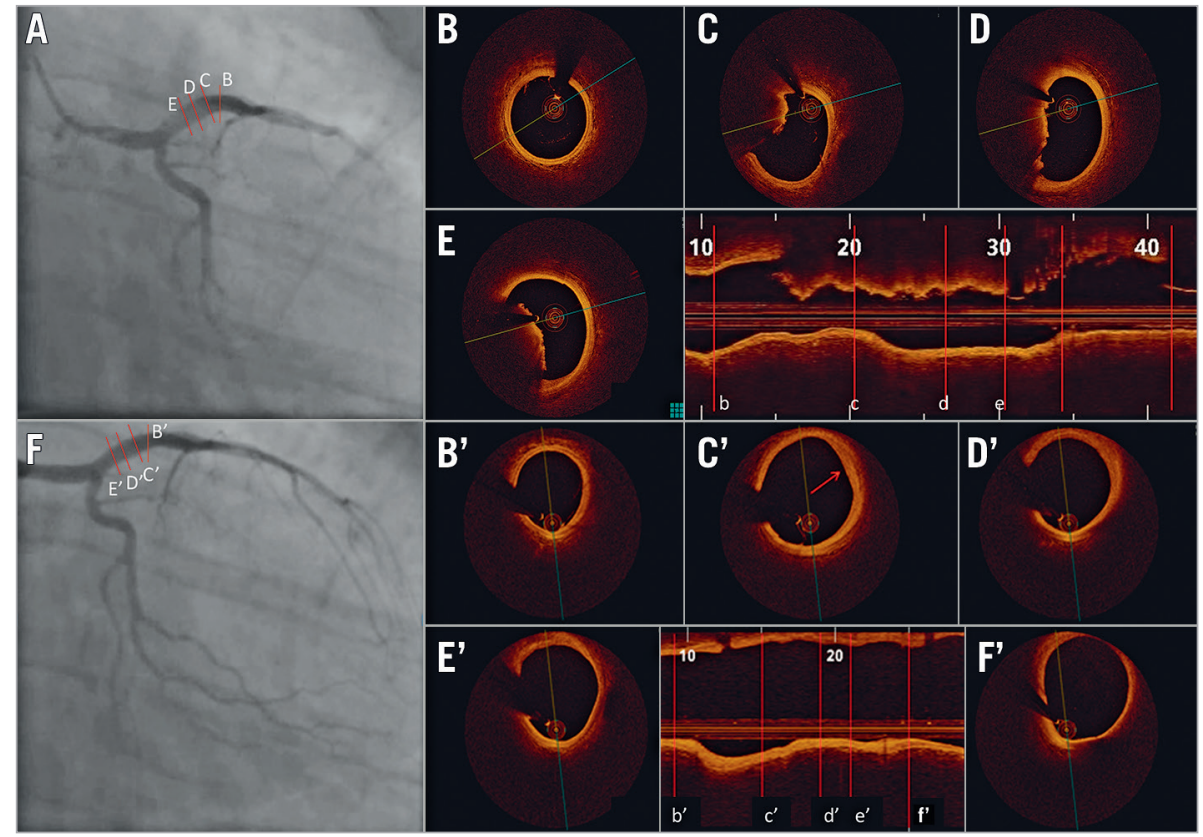

Figure 6. Acute coronary syndrome secondary to thrombotic lesion managed with medical therapy using optical coherence tomography guidance. A 33-year-old male current smoker presented to the emergency department with chest pain and positive cardiac biomarkers. A) Coronary angiography revealed haziness in the proximal left anterior descending (LAD) artery. Optical coherence tomography (OCT) on cross-sectional and longitudinal images $(B, b)$ demonstrated a normal segment at the mid-LAD segment but with $(C-E$, $c-e)$ large nonocclusive thrombus proximally (minimal lumen area: $9 \mathrm{~mm}^{2}$ ). The patient was treated with glycoprotein IIb/IIIa antagonists for 48 hours and was subsequently discharged on triple therapy with warfarin, aspirin, and clopidogrel. The patient returned for angiography and OCT six weeks later. On cross-sectional and longitudinal analysis of the images that were co-registered with the index OCT, there was ( $\left.B^{\prime}, b^{\prime}\right)$ a normal mid-LAD artery segment, and $\left(C^{\prime}-F^{\prime}, c^{\prime}-f^{\prime}\right)$ complete resolution of thrombus with a possible area of healed erosion $\left(C^{\prime}, c^{\prime}\right)$. Images courtesy of Mullasari Ajit Sankardas, MD, DM, FRCP.

Recently, OCT has been shown to be beneficial in the diagnostic work-up of MI with non-obstructive coronary arteries (MINOCA) ${ }^{63}$. In women with MINOCA (i.e., coronary artery disease with $<50 \%$ diameter stenosis on angiography), a definite or possible culprit lesion was identified by OCT in $46 \%$ of the participants. The most common OCT findings were plaque rupture, intraplaque cavity, and layered plaque (Supplementary Figure 10). Similarly, in patients with non-ST-segment elevation ACS (NSTEACS) and multivessel disease, coronary angiography alone may be insufficient to identify the culprit lesions ${ }^{64}$. An identifiable culprit lesion may be absent in up to $30 \%$ of patients with NSTEACS, and $>10 \%$ of patients may have multiple culprit lesions on angiography. Even in patients presenting with ST-segment elevation MI (STEMI), the culprit lesions may not be identifiable in up to $4-10 \%$ of cases by angiography alone ${ }^{65}$. OCT can be helpful in resolving the ambiguity regarding the culprit plaques in these instances.

Subclinical atherothrombosis and plaque healing may lead to rapid plaque progression. The histopathologic healed plaque has a layered appearance when imaged using $\mathrm{OCT}^{66-69}$. Layered plaques were identified in three quarters of patients with acute MI, especially in the culprit plaques of patients with ST-segmentelevation MI. Layered plaques had a limited, focal distribution in the left anterior descending artery and left circumflex artery but were more evenly distributed in the right coronary artery and were characterised by greater lumen narrowing at both culprit and nonculprit sites ${ }^{69}$.

Finally, spontaneous dissections and intramural haematoma are readily identified on OCT and are occasionally found in patients presenting with ACS with or without angiographically discrete lesions (Supplementary Figure 11) ${ }^{70}$.

\section{OCT: HIGH-RISK PLAQUES}

OCT has been used to identify lesions with high-risk features (i.e., "vulnerable plaques") that may be associated with ACS, including TCFAs and inflamed plaques, which are identified with macrophage infiltration. Compared with IVUS-based modalities, the ability to measure cap thickness on OCT due to its superior resolution improves detection of TCFAs. Notably, while validated in prospective studies on the natural history of atherosclerosis ${ }^{71-73}$, TCFAs were removed from the high-risk plaque characteristics in the recent PROSPECT $\mathrm{II}^{74}$ and PROSPECT ABSORB ${ }^{75}$ studies, due to the diagnostic ambiguity that exists with regard to the identification of TCFAs on IVUS.

In the CLIMA study, in 1,003 patients undergoing OCT of the proximal left anterior descending artery, 37 patients (3.7\%) suffered a "hard event" (25 cardiac deaths and 13 target segment MI) 


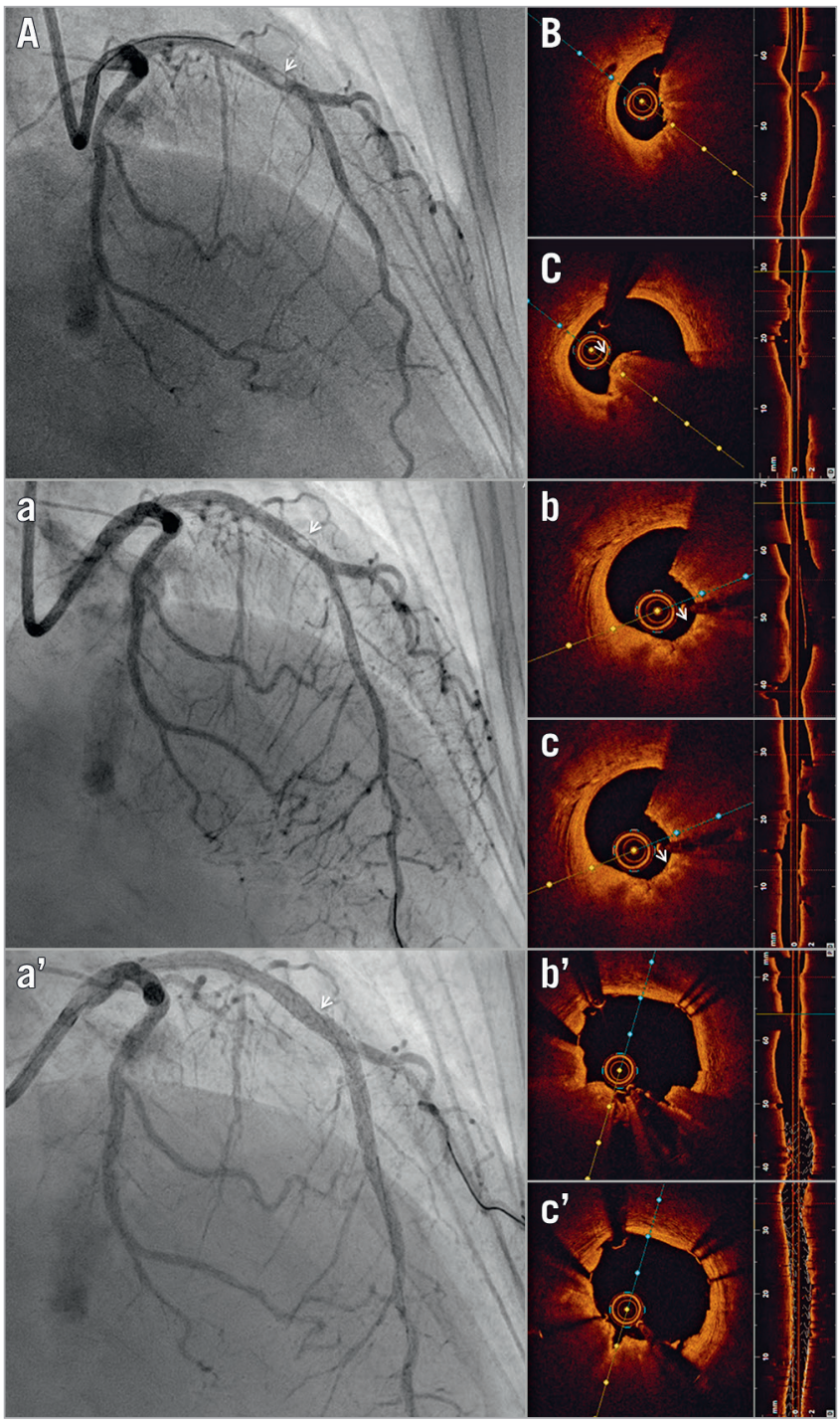

Figure 7. Optical coherence tomography-guided percutaneous coronary intervention on a calcific protruding nodule.

A) Angiography shows a mid-left anterior descending (LAD) nodular obstruction (arrowhead). B) Optical coherence tomography (OCT) imaging reveals a small minimal lumen area and $(C)$ confirms the aetiology of the obstruction to be a calcific protruding nodule (arrowhead). (a) Following rotational atherectomy, the lesion appears mildly less stenotic angiographically (arrowhead). (b, c) OCT imaging reveals significant debulking of the calcified nodule (arrowhead). Note the smooth polished surface in the direction of the catheter bias where the burr exerts its action. $\left(a^{\prime}\right)$ Final angiography shows mild residual diameter stenosis (arrowhead). $\left(b^{\prime}, c^{\prime}\right)$ OCT imaging confirms further luminal gain and exclusion of the calcific nodule, with minimal eccentricity and malapposition.

at one year ${ }^{76}$. When all four predefined high-risk plaque features (MLA $<3.5 \mathrm{~mm}^{2}$, TCFA with cap thickness $<75 \mu \mathrm{m}$, lipid arc $>180^{\circ}$, and macrophage infiltration) were present, the hazard ratio for the primary endpoint was as high as 7.54. In a study of 1,474 patients, Xing et $\mathrm{al}^{77}$ reported that OCT-detected lipidrich plaques were associated with a higher rate of major adverse cardiac events (cardiac death, acute MI, and ischaemia-driven revascularisation) compared with non-lipidic plaques at two years.

Nevertheless, several issues regarding the detection of vulnerable plaques by OCT and its prognostic value, particularly with TCFAs $^{78,79}$, remain unresolved, including modest inter-observer agreement for cap thickness and lipid arc measurements ${ }^{80}$, artefacts mimicking lipid ${ }^{81}$, and exceedingly low event rates in patients with TCFAs $^{77}$. Some features of vulnerable plaques, such as intraplaque haemorrhage, are not readily identifiable on OCT alone. Future studies are warranted to establish whether OCT alone or in combination with other imaging modalities ${ }^{82}$, such as hybrid IVUS/ $\mathrm{OCT}^{8}$, near-infrared autofluorescence to detect necrotic core ${ }^{83}$ or intraplaque haemorrhage ${ }^{84}$, or near-infrared spectroscopy to detect lipid (Supplementary Figure 12), will have clinical impact.

It is plausible that detection of vulnerable plaques in selected patient populations, including patients at high risk of future events (e.g., with prior ACS or diabetics), may be of clinical significance. Indeed, in the OCT substudy of the COMPLETE trial, nearly 50\% of patients had at least one obstructive non-culprit lesion containing TCFA. Obstructive lesions more commonly harboured vulnerable plaque morphology, including TCFA, high lipid burden, macrophages, and cholesterol crystals, than non-obstructive lesions. These findings were postulated to drive the benefit of routine PCI of the obstructive non-culprit lesions in patients with STEMI and multivessel disease ${ }^{85}$. In the recent COMBINE OCT-FFR study of diabetic patients with intermediate lesions and fractional flow reserve $>0.80$, the presence of TCFA (in $25 \%$ of lesions) was associated with a 4.7-fold increase in the primary endpoint of cardiac death, target vessel MI, target lesion revascularisation, or hospitalisation for angina (Combined optical coherence tomography and fractional flow reserve assessment to better predict adverse event outcomes in DM patients: COMBINE (OCT-FFR) study. Presented by E. Kedhi at TCT Connect 2020, 14 October 2020). This increase in event rates was driven mostly by higher rates of target lesion revascularisation and hospitalisation for angina, with a rate for target vessel MI of $4.1 \%$.

\section{OCT: SHORT- AND LONG-TERM ASSESSMENT OF STENTS}

OCT is useful in surveillance of stents and bioresorbable scaffolds, particularly in assessment of neointima, neoatherosclerosis, resorption of scaffolds, and mechanisms of stent failure and stent thrombosis. Strut coverage is frequently used as a surrogate for healing around the stent struts, assuming that it represents endothelialisation; however, strut coverage may be due to fibrin ${ }^{86}$, and resolution of OCT is not adequate to visualise endothelial cells ${ }^{87}$.

Neointimal patterns on OCT have been correlated to specific tissue types, with the "homogenous pattern" often correlating with smooth muscle cells within collagenous and proteoglycan matrix, the "layered pattern" with healed neointimal rupture or erosion, and "high intensity with high attenuation" with superficial macrophage accumulation; nonetheless, each pattern may also correlate with other tissue types ${ }^{88}$. Hybrid imaging with OCT may overcome the limitations of OCT alone in determining the components of neointima and assessment of post-stenting healing ${ }^{82}$. 
Chronic inflammation and impaired endothelial function with increased lipid uptake contribute to the development of late neointima within the stent struts, which is a mechanism for stent restenosis and late ( $>30$ days) and very late ( $>12$ months) stent thrombosis $^{89-92}$. Strut malapposition and underexpansion were associated with acute stent thrombosis $(<24$ hours post PCI) and subacute stent thrombosis (1-30 days). It is important to note that OCT findings in stent thrombosis may be mechanistically related but, strictly speaking, causality cannot be inferred from registry data. Based on these observations, the European Society of Cardiology guidelines for revascularisation recommend that, in the cases of stent failure, OCT use should be considered to identify and correct the underlying mechanical factors ${ }^{93}$.

\section{OCT VERSUS IVUS VERSUS ANGIOGRAPHY IN REGISTRIES AND RANDOMISED TRIALS}

Evidence suggesting a clinical benefit for using IVUS for PCI guidance has been shown in several registries ${ }^{94}$, randomised trials $^{4,95}$, and meta-analyses ${ }^{96,97}$. In randomised trials, IVUS guidance is associated with a reduction in major adverse cardiac events, and in meta-analyses, with reduced cardiovascular mortality, MI, and stent thrombosis compared with angiography guidance ${ }^{7}$. The differences between IVUS and OCT, their relative merits, and specific applications in different lesion types and clinical scenarios, have been reviewed previously ${ }^{98}$.

As OCT is a relatively new modality, it currently lacks the robust evidence that has accumulated for IVUS-guided PCI. Completed and enrolling trials of OCT-guided PCI are shown in

Table 2. In the earliest studies, OCT was demonstrated to impact significantly on the procedural strategy. In the CLI-OPCI trial of 670 patients comparing angiography with an OCT-guided strategy, adverse features requiring further intervention were identified in $35 \%$ of cases on $\mathrm{OCT}^{99}$. Moreover, OCT guidance was associated with a significantly lower risk of MI or cardiac death at one year after adjustment for potential confounders.

The OPINION trial ${ }^{22}$, which included 829 patients, was the first clinical outcomes-based randomised trial that compared OCT- and IVUS-guided PCI, with a primary endpoint of target vessel failure

\section{Table 2. Summary of currently available data on optical coherence tomography versus intravascular ultrasound versus angiography for}

percutaneous coronary intervention guidance.

\begin{tabular}{|c|c|c|c|c|}
\hline Study & Design & Comparators and sample size & Primary endpoint & Results \\
\hline CLI-OPCI ${ }^{99}$ & RCT & $\begin{array}{c}335 \text { OCT- vs } 335 \text { angiography-guided } \\
\text { PCl }\end{array}$ & $\begin{array}{l}\text { Cardiac death or non-fatal Ml } \\
\text { at } 1 \text { year }\end{array}$ & $\begin{array}{l}\text { OCT lower risk of cardiac death }(1.2 \% \text { vs } 4.5 \%, p=0.010) \text {, } \\
\text { cardiac death or } \mathrm{MI}(6.6 \% \text { vs } 13.0 \%, p=0.006) \text {, and composite of } \\
\text { cardiac death, MI, or repeat revascularisation ( } 9.6 \% \text { vs } 14.8 \% \text {, } \\
p=0.044) \text {. }\end{array}$ \\
\hline $\begin{array}{l}\text { ILUMIEN III: OPTIMIZE } \\
\text { PCl21 }\end{array}$ & RCT & $\begin{array}{l}158 \text { OCT- vs } 146 \text { IVUS- vs } \\
146 \text { angiography-guided PCI }\end{array}$ & $\begin{array}{l}\text { MSA assessed by OCT } \\
\text { post PCI }\end{array}$ & $\begin{array}{l}\text { Median MSA by OCT } 5.79 \mathrm{~mm}^{2} \text { (IQR 4.54-7.34), IVUS } 5.89 \mathrm{~mm}^{2} \\
\text { (4.67-7.80), angiography } 5.49 \mathrm{~mm}^{2}(4.39-6.59) \text {. OCT guidance } \\
\text { non-inferior to IVUS guidance (1-sided } 97.5 \% \text { lower CI: } \\
\left.-0.70 \mathrm{~mm}^{2}, p=0.001 \text { ), but not superior ( } p=0.42\right) \text {. OCT guidance } \\
\text { also not superior to angiography guidance ( } p=0.12 \text { ). }\end{array}$ \\
\hline Buccheri et al ${ }^{96}$ & Meta-analysis & $\begin{array}{l}31 \text { studies and } \\
17,882 \text { patients }\end{array}$ & $\begin{array}{l}\text { All-cause mortality at } \\
1-36 \text { months }\end{array}$ & $\begin{array}{l}\text { Significant reduction in MACE (IVUS; OR 0.79, } 95 \% \text { CI: } 0.67-0.91 \text {, } \\
\text { and OCT; OR 0.68, 95\% Cl: 0.49-0.97) and cardiovascular death } \\
\text { (IVUS; OR 0.47, 95\% Cl: 0.32-0.66, and OCT; OR 0.31, } 95 \% \text { Cl: } \\
0.13-0.66 \text { ). }\end{array}$ \\
\hline DOCTORS ${ }^{116}$ & RCT & $\begin{array}{l}120 \text { OCT- vs } 120 \text { angiography-guided } \\
\text { PCl }\end{array}$ & FFR value post $\mathrm{PCl}$ & $\begin{array}{l}\text { Higher FFR using OCT guidance }(0.94 \pm 0.04 \text { vs } 0.92 \pm 0.05 \text {, } \\
p=0.005) \text { compared with angiography. }\end{array}$ \\
\hline $\begin{array}{l}\text { Pan-London PCl } \\
\text { cohort }^{2}\end{array}$ & Registry & $\begin{array}{l}\text { 1,149 0CT- vs } 10,971 \text { IVUS- } \\
\text { vs 75,046 angiography-guided PCI }\end{array}$ & $\begin{array}{l}\text { All-cause mortality at } \\
4.8 \text { years }\end{array}$ & $\begin{array}{l}\text { Reduced mortality in OCT-guided PCI }(7.7 \%) \text { vs either } \\
\text { IVUS- }(12.2 \%) \text { or angiography-guided }(15.7 \%, p<0.0001) \mathrm{PCl} \text {. }\end{array}$ \\
\hline OPINION22 & RCT & 414 OCT- vs 415 IVUS-guided PCI & TVF at 1 year & $\begin{array}{l}\text { TVF in } 5.2 \% \text { undergoing } 0 \text { FDI-guided PCl and in } 4.9 \% \text { undergoing } \\
\text { IVUS-guided PCl, demonstrating non-inferiority (HR 1.07, upper } \\
\text { limit of } 1 \text {-sided } 95 \% \mathrm{Cl}: 1.80, p=0.042 \text { ). }\end{array}$ \\
\hline $\begin{array}{l}\text { OCCUPI } \\
\text { (NCT03625908) }\end{array}$ & RCT & $\begin{array}{l}\text { OCT- vs angiography-guided PCI in } \\
1,604 \text { patients }\end{array}$ & MACE at 1 year & $\begin{array}{l}\text { Complex lesions: ACS, CT0, long lesion: expected stent length } \\
\geq 28 \mathrm{~mm} \text {, calcified lesion, bifurcation, unprotected left main, } \\
\text { small vessel }(<2.5 \mathrm{~mm}) \text {, intracoronary thrombus, stent } \\
\text { thrombosis, ISR. }\end{array}$ \\
\hline $\begin{array}{l}\text { OCTIVUS } \\
\text { (NCT03394079) }\end{array}$ & RCT & $\begin{array}{l}\text { OCT- vs angiography-guided } \mathrm{PCl} \text { in } \\
2,000 \text { patients }\end{array}$ & TVF at 1 year & Open label. \\
\hline ILUMIEN IV 104 & RCT & $\begin{array}{l}\text { OCT- vs angiography-guided PCl in } \\
2,550 \text { high clinical or angiographic } \\
\text { risk PCl }\end{array}$ & $\begin{array}{l}\text { MSA assessed by OCT post } \\
\text { PCl; TVF at 1-2 years }\end{array}$ & $\begin{array}{l}\text { High clinical risk: diabetes mellitus. High angiographic risk: } \\
\text { NSTEMI, long lesion: expected stent length } \geq 28 \mathrm{~mm}, 2 \text {-stent } \\
\text { bifurcation, severe calcification, CTO, ISR. }\end{array}$ \\
\hline OCTOBER ${ }^{105}$ & RCT & $\begin{array}{l}\text { OCT- vs angiography-guided PCI in } \\
1,200 \text { complex bifurcation lesions }\end{array}$ & MACE at 2 years & $\begin{array}{l}\text { Two-stent technique or 1-stent technique with kissing balloon } \\
\text { inflation. }\end{array}$ \\
\hline
\end{tabular}

ACS: acute coronary syndromes; CTO: chronic total occlusion; FFR: fractional flow reserve; ISR: in-stent restenosis; IVUS: intravascular ultrasound; MACE: major adverse cardiovascular events; MI: myocardial infarction; MSA: minimal stent area; OCT: optical coherence tomography; OFDI: optical frequency domain imaging; OR: odds ratio; PCI: percutaneous coronary intervention; RCT: randomised controlled trial; TVF: target vessel failure 
at one year. The primary endpoint did not differ between the two imaging modalities, with OCT demonstrating non-inferiority compared with IVUS. Similarly, the major secondary endpoint of angiographic binary restenosis was not different at eight months. One of the criticisms of the OPINION trial is that stent sizing with IVUS was guided by the EEL-based diameter measurements, whereas, with OCT, stents were selected based on lumen diameter measurements ${ }^{98}$. Compared with IVUS, visualisation of the EEL is more challenging on OCT, particularly in the presence of lipidic plaque. The OPINION trial and previous studies have shown that EEL-based stent sizing strategies result in the selection of larger diameter balloons and stents and more frequent post-dilation compared with lumen-based diameter measurements ${ }^{100,101}$. As lower MSA has consistently been shown to be a pre-eminent cause of late DES failure ${ }^{3,44-50}$, the difference in stent sizing strategy in these previous studies may have been a disadvantage for OCT in comparison with IVUS.

The ILUMIEN III trial ${ }^{21}$ compared OCT-, IVUS-, and angiography-guided PCI using an EEL-based sizing strategy in the OCT arm. In 450 patients, OCT-guided PCI was non-inferior to IVUS-guided PCI in terms of final MSA (but not superior to angiography); however, OCT-detected major stent edge dissections (dissection flap $>60^{\circ}$ or $>3 \mathrm{~mm}$ in length) were less common in the OCT-guided arm versus the IVUS-guided arm. OCT guidance also resulted in more frequent post-dilation, larger maximum balloon size, and higher balloon pressure in comparison to angiography guidance alone. One-year clinical outcomes comparing the three groups were similar, although the trial was grossly underpowered to detect any differences ${ }^{102}$. Similar findings were recently reported in the smaller MISTIC-I trial $(\mathrm{n}=109)^{103}$

Insights into the potential benefit for OCT guidance to improve clinical outcomes come from a much larger population of patients in a network meta-analysis of 17,882 patients $^{82}$. In this analysis, important reductions in both major adverse cardiac events and cardiovascular mortality using OCT- or IVUS-guided versus angiography-guided PCI were identified. Data supporting the utility of OCT guidance in PCI are also provided from the large Pan-London PCI cohort registry ${ }^{2}$. In 123,764 patients who underwent PCI in London between 2005 and 2015, OCT was used in 1,149 (1.3\%) and IVUS in $10,971(12.6 \%)$ patients. OCT-guided procedures were associated with greater procedural success rates and reduced rates of in-hospital major adverse cardiac events. A significant difference in mortality was observed between patients who underwent OCT-guided PCI (7.7\%) compared with patients who underwent either IVUS-guided (12.2\%) or angiography-guided (15.7\%) PCI $(p<0.0001)$. These results persisted after propensity matching in the OCT versus angiography guidance cohorts (hazard ratio [HR] 0.39, 95\% confidence interval [CI]: 0.21-0.77; $\mathrm{p}=0.0008$ ).

The ILUMIEN IV ${ }^{104}$ and OCTOBER trials ${ }^{105}$ are two large ongoing randomised trials that aim to determine the clinical impact of OCT-guided versus angiography-guided PCI. ILUMIEN IV is a prospective, single-blind, global, multicentre randomised trial comparing OCT-defined EEL-based PCI guidance to angiography-guided PCI in complex patients and coronary lesions. The OCTOBER trial will compare two-year clinical outcomes after OCT-guided versus angiography-guided revascularisation in patients requiring complex bifurcation stent implantation (Supplementary Figure 13).

\section{OCT in progress and future iterations}

Blood clearance needed for OCT image acquisition increases the radiocontrast burden, which is undesirable in patients with renal disease. Several alternative flushing agents have been investigated $^{106}$. Low-molecular-weight dextran produces image quality comparable to radiocontrast ${ }^{107,108}$; however, dextran is excreted from the kidneys and has the potential to cause renal injury by the same mechanism as contrast ${ }^{108}$. Carbon dioxide has been used for peripheral angiography ${ }^{109}$; however, it is unsuitable for coronary imaging due to precipitation of myocardial ischaemia. Although a clear crystalloid solution such as Ringer's solution has been used in the older occlusive OCT acquisition technique, and more recently normal saline has been shown to produce images with similar quality to contrast OCT acquisitions (Figure 8) ${ }^{110}$, problems with blood mixing and potential for precipitation of arrhythmia with non-contrast flushes exist. Alternative non-contrast flush media with similar biocompatibility, viscosity, blood clearance capability, and optical transparency are needed to address this issue and are being investigated.

Ongoing developments have focused on engineering new OCT systems to increase the speed of OCT acquisition (e.g., within a single cardiac cycle with full sampling both cross-sectionally and longitudinally) ${ }^{111}$, spatial resolution (e.g., "micro OCT" with $\sim 2 \mu \mathrm{m}$ isotropic resolution, capable of identifying cellular [macrophages, endothelial cells] and sub-cellular [extracellular cholesterol crystals] structures ${ }^{112}$ ), and penetration depth. Further studies are needed to validate these new advances and their putative clinical impact.

Although intravascular imaging and intracoronary physiology are often grouped together, there is a dichotomy between the use of imaging and that of physiology to guide PCI in clinical practice. Which modality has a greater clinical utility is a matter of great debate. A recent trial ${ }^{113}$ compared OCT guidance versus fractional flow reserve guidance in patients with angiographically intermediate coronary lesions in a single-centre, prospective, 1:1 randomised trial. In 350 patients, the primary endpoint of major adverse cardiac events or significant angina at 13 months occurred in $14.8 \%$ of patients in the physiology arm and in $8.0 \%$ in the OCT arm $(p=0.048)^{113}$. In this regard, OCT-based flow ratios may provide the benefit of both modalities combined. The optical flow ratio has been developed and validated against fractional flow reserve to determine the functional significance of coronary stenosis (Figure 9) ${ }^{114}$. The currently enrolling FUSION trial (NCT04356027) will assess the accuracy of off-line, OCTbased virtual flow reserve against fractional flow reserve on the ILUMIEN $^{\text {TM }}$ OPTIS ${ }^{\mathrm{TM}}$ platform (Abbott Vascular). 


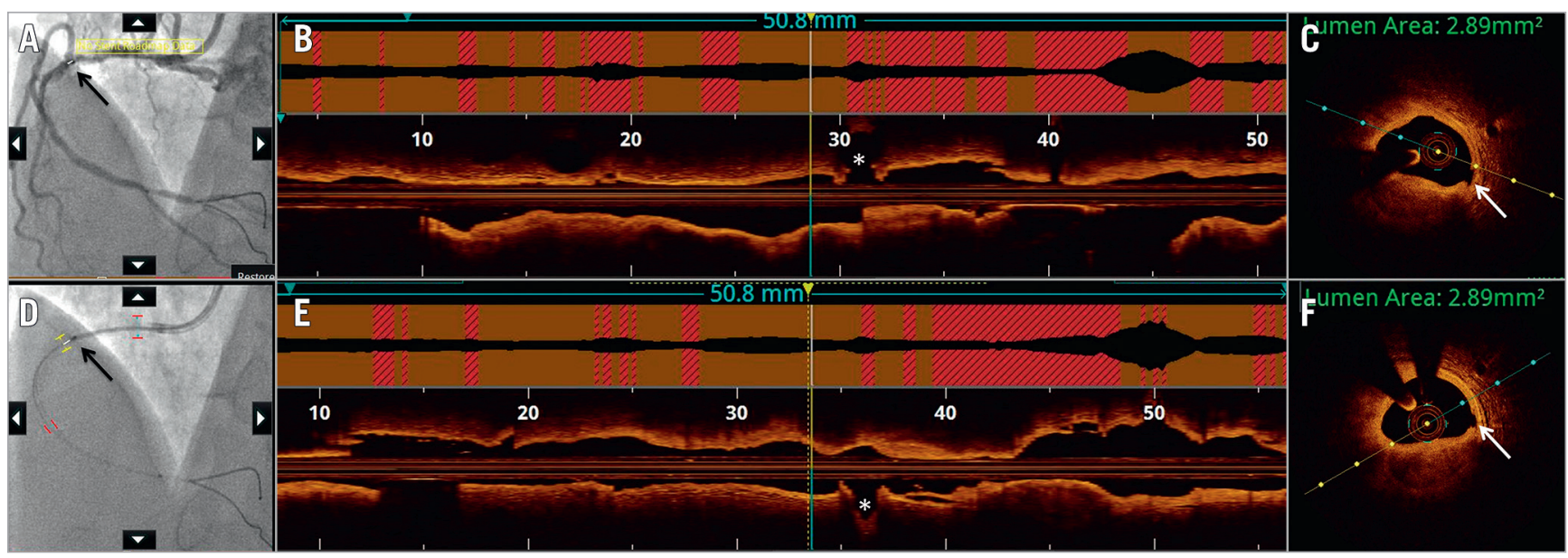

Figure 8. Saline as flush medium for image acquisition by optical coherence tomography. Optical coherence tomography (OCT) images acquired using the standard radiocontrast to displace blood $(A-C)$ are compared with image acquisition by saline (D-F). A) Angiographic co-registration (white bar and black arrow) with corresponding segment on longitudinal frame on OCT (yellow and blue vertical lines), just proximal to the acute marginal branch (asterisk) (B). C) A cross-sectional frame with luminal area measured at $2.89 \mathrm{~mm}^{2}$ due to stenosis by nodular calcification. Note the small intimal disruption (white arrow). D) Co-registration (black bar and black arrow) with OCT acquired using saline at the same location as the radiocontrast acquisition, proximal to the acute marginal branch (asterisk) (E). F) The cross-sectional area at the same OCT frame as in (C) also measures $2.89 \mathrm{~mm}^{2}$, with calcification and small intimal disruption (white arrow) similarly identifiable.

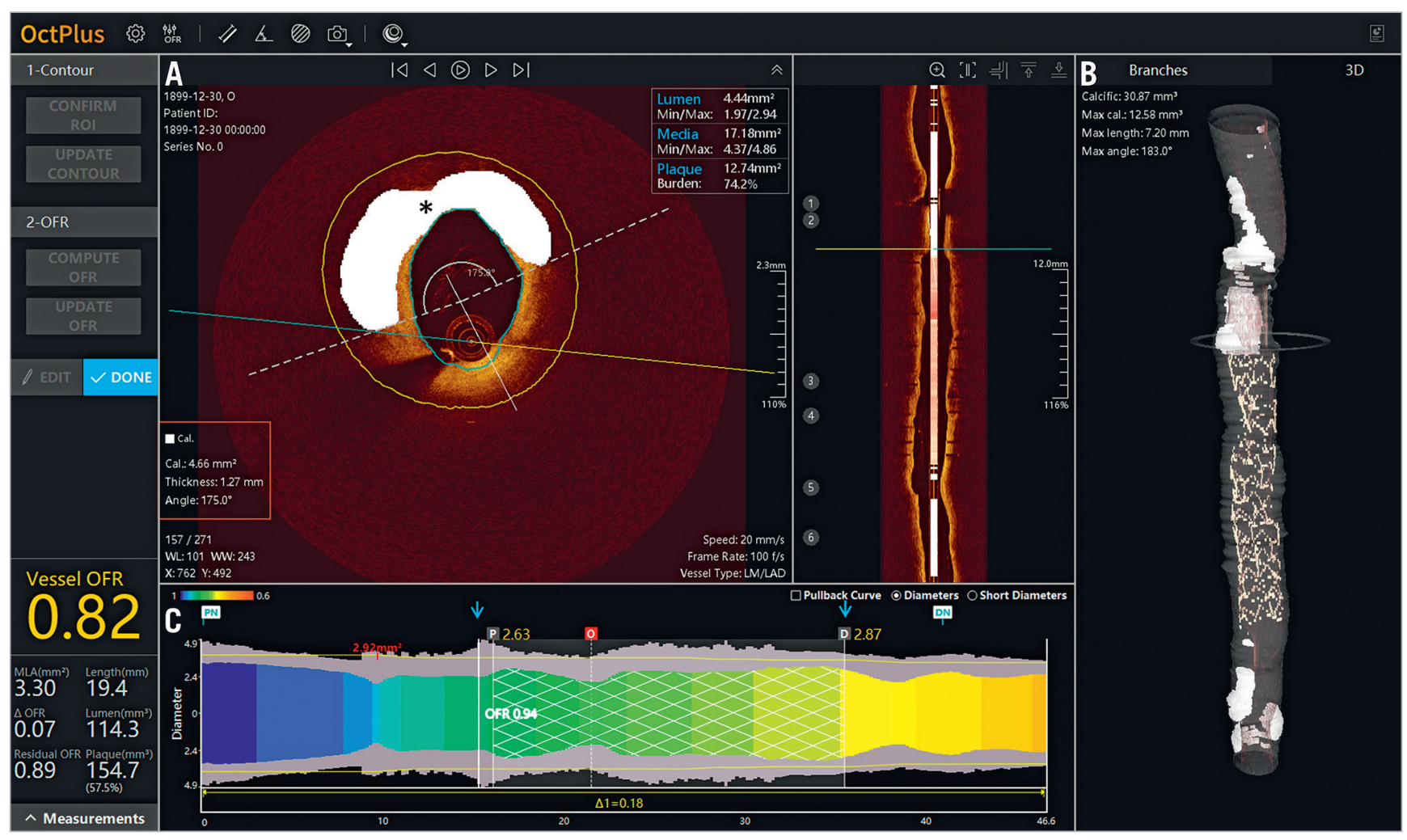

Figure 9. Plaque characterisation with combined optical coherence tomography and fractional flow reserve. New optical coherence tomography (OCT) system demonstrates $(A, B)$ automated plaque characterisation (calcium denoted in white marked by asterisk) with details relevant to lesion preparation (red box). C) Using a lumen profile, the virtual OCT-derived fractional flow reserve (FFR) is displayed as a coloured map, showing areas of potential ischaemia (yellow), FFR within the stented segment (blue arrows), as well as for the whole vessel. Images courtesy of Shengxian $\mathrm{Tu}, \mathrm{PhD}$. 
Assessment of vascular morphology on OCT remains a manual task and is thus time-consuming and labour-intensive. Promising progress has been made in developing algorithms for automated tissue classification using texture, attenuation, or other tissue characteristics on OCT that may aid in automated OCT image segmentation and interpretation (Figure 9, Supplementary Figure 12).

\section{Conclusion}

Intravascular OCT provides a wealth of data on coronary structures and pathologies, with rapidly progressing applications for the diagnosis and management of coronary artery disease. Systematic efforts are ongoing to educate the interventional cardiology community on the appropriate use and interpretation of OCT images, using practical algorithmic approaches. Robust evidence from the ongoing randomised trials on the impact of OCT guidance in improving clinical outcomes could increase the adoption of this imaging modality in clinical practice.

\section{Conflict of interest statement}

Z.A. Ali reports institutional research grants to Columbia University from Abbott and Cardiovascular Systems Inc., being a consultant to Amgen, AstraZeneca, and Boston Scientific, and having equity in Shockwave Medical. G.S. Mintz reports honoraria from Abiomed, Boston Scientific, Medtronic, and Philips. A. Maehara reports grant support from and being a consultant for Abbott Vascular and Boston Scientific. R.A. Shlofmitz reports speaker fees from Shockwave Medical. The other authors have no conflicts of interest to declare.

\section{References}

1. Maehara A, Mintz GS, Witzenbichler B, Weisz G, Neumann FJ, Rinaldi MJ, Metzger DC, Henry TD, Cox DA, Duffy PL, Brodie BR, Stuckey TD, Mazzaferri EL Jr, McAndrew T, Généreux P, Mehran R, Kirtane AJ, Stone GW. Relationship Between Intravascular Ultrasound Guidance and Clinical Outcomes After Drug-Eluting Stents. Circ Cardiovasc Interv. 2018;11:e06243.

2. Jones DA, Rathod KS, Koganti S, Hamshere S, Astroulakis Z, Lim P, Sirker A, O'Mahony C, Jain AK, Knight CJ, Dalby MC, Malik IS, Mathur A, Rakhit R, Lockie T, Redwood S, MacCarthy PA, Desilva R, Weerackody R, Wragg A, Smith EJ, Bourantas CV. Angiography Alone Versus Angiography Plus Optical Coherence Tomography to Guide Percutaneous Coronary Intervention: Outcomes From the PanLondon PCI Cohort. JACC Cardiovasc Interv. 2018;11:1313-21.

3. Park H, Ahn JM, Kang DY, Lee JB, Park S, Ko E, Cho SC, Lee PH, Park DW, Kang SJ, Lee SW, Kim YH, Lee CW, Park SW, Park SJ. Optimal Stenting Technique for Complex Coronary Lesions: Intracoronary Imaging-Guided Pre-Dilation, Stent Sizing, and Post-Dilation. JACC Cardiovasc Interv. 2020;13:1403-13.

4. Hong SJ, Mintz GS, Ahn CM, Kim JS, Kim BK, Ko YG, Kang TS, Kang WC, Kim YH, Hur SH, Hong BK, Choi D, Kwon H, Jang Y, Hong MK; IVUS-XPL Investigators. Effect of Intravascular Ultrasound-Guided Drug-Eluting Stent Implantation: 5-Year Follow-Up of the IVUS-XPL Randomized Trial. JACC Cardiovasc Interv. 2020;13:62-71

5. Zhang J, Gao X, Kan J, Ge Z, Han L, Lu S, Tian N, Lin S, Lu Q, Wu X, Li Q, Liu Z, Chen Y, Qian X, Wang J, Chai D, Chen C, Li X, Gogas BD, Pan T, Shan S, Ye F, Chen SL. Intravascular Ultrasound Versus Angiography-Guided Drug-Eluting Stent Implantation: The ULTIMATE Trial. J Am Coll Cardiol. 2018;72:3126-37.

6. di Mario C, Koskinas KC, Räber L. Clinical Benefit of IVUS Guidance for Coronary Stenting: The ULTIMATE Step Toward Definitive Evidence? J Am Coll Cardiol. 2018;72:3138-41

7. Elgendy IY, Mahmoud AN, Elgendy AY, Mintz GS. Intravascular UltrasoundGuidance Is Associated With Lower Cardiovascular Mortality and Myocardial Infarction for Drug-Eluting Stent Implantation - Insights From an Updated MetaAnalysis of Randomized Trials. Circ J. 2019;83:1410-3.
8. Ono M, Kawashima H, Hara H, Gao C, Wang R, Kogame N, Takahashi K, Chichareon P, Modolo R, Tomaniak M, Wykrzykowska JJ, Piek JJ, Mori I, Courtney BK, Wijns W, Sharif F, Bourantas C, Onuma Y, Serruys PW. Advances in IVUS/OCT and Future Clinical Perspective of Novel Hybrid Catheter System in Coronary Imaging. Front Cardiovasc Med. 2020;7:119.

9. Barlis P, Gonzalo N, Di Mario C, Prati F, Buellesfeld L, Rieber J, Dalby MC, Ferrante G, Cera M, Grube E, Serruys PW, Regar E. A multicentre evaluation of the safety of intracoronary optical coherence tomography. EuroIntervention. 2009;5:90-5.

10. Räber L, Mintz GS, Koskinas KC, Johnson TW, Holm NR, Onuma Y, Radu MD, Joner M, Yu B, Jia H, Meneveau N, de la Torre Hernandez JM, Escaned J, Hill J, Prati F, Colombo A, Di Mario C, Regar E, Capodanno D, Wijns W, Byrne RA, Guagliumi G. Clinical use of intracoronary imaging. Part 1: guidance and optimization of coronary interventions. An expert consensus document of the European Association of Percutaneous Cardiovascular Interventions. EuroIntervention. 2018; 14:656-77.

11. Fujino A, Mintz GS, Matsumura M, Lee T, Kim SY, Hoshino M, Usui E, Yonetsu T, Haag ES, Shlofmitz RA, Kakuta T, Maehara A. A new optical coherence tomographybased calcium scoring system to predict stent underexpansion. EuroIntervention. 2018; $13:$ e2182-9

12. Ali ZA, Galougahi KK. Shining light on calcified lesions, plaque stabilisation and physiologic significance: new insights from intracoronary OCT. EuroIntervention. 2018;13:e2105-8

13. Fujino A, Mintz GS, Lee T, Hoshino M, Usui E, Kanaji Y, Murai T, Yonetsu T, Matsumura M, Ali ZA, Jeremias A, Moses JW, Shlofmitz RA, Kakuta T, Maehara A Predictors of Calcium Fracture Derived From Balloon Angioplasty and its Effect on Stent Expansion Assessed by Optical Coherence Tomography. JACC Cardiovasc Interv. 2018;11:1015-7.

14. Ino Y, Kubo T, Matsuo Y, Yamaguchi T, Shiono Y, Shimamura K, Katayama Y, Nakamura T, Aoki H, Taruya A, Nishiguchi T, Satogami K, Yamano T, Kameyama T, Orii M, Ota S, Kuroi A, Kitabata H, Tanaka A, Hozumi T, Akasaka T. Optical Coherence Tomography Predictors for Edge Restenosis After Everolimus-Eluting Stent Implantation. Circ Cardiovasc Interv. 2016;9:e004231.

15. Prati F, Romagnoli E, Gatto L, La Manna A, Burzotta F, Limbruno U, Versaci F, Fabbiocchi F, Di Giorgio A, Marco V, Ramazzotti V, Di Vito L, Trani C, Porto I, Boi A, Tavazzi L, Mintz GS. Clinical Impact of Suboptimal Stenting and Residual Intrastent Plaque/Thrombus Protrusion in Patients With Acute Coronary Syndrome: The CLIOPCI ACS Substudy (Centro per la Lotta Contro L'Infarto-Optimization of Percutaneous Coronary Intervention in Acute Coronary Syndrome). Circ Cardiovasc Interv. 2016;9:e003726.

16. Prati F, Romagnoli E, La Manna A, Burzotta F, Gatto L, Marco V, Fineschi M, Fabbiocchi F, Versaci F, Trani C, Tamburino C, Alfonso F, Mintz GS. Long-term consequences of optical coherence tomography findings during percutaneous coronary intervention: the Centro Per La Lotta Contro L'infarto - Optimization Of Percutaneous Coronary Intervention (CLI-OPCI) LATE study. EuroIntervention. 2018;14:e443-51.

17. Prati F, Kodama T, Romagnoli E, Gatto L, Di Vito L, Ramazzotti V, Chisari A, Marco V, Cremonesi A, Parodi G, Albertucci M, Alfonso F. Suboptimal stent deployment is associated with subacute stent thrombosis: optical coherence tomography insights from a multicenter matched study. From the CLI Foundation investigators: the CLI-THRO study. Am Heart J. 2015;169:249-56

18. Prati F, Romagnoli E, Burzotta F, Limbruno U, Gatto L, La Manna A, Versaci F, Marco V, Di Vito L, Imola F, Paoletti G, Trani C, Tamburino C, Tavazzi L, Mintz GS Clinical Impact of OCT Findings During PCI: The CLI-OPCI II Study. JACC Cardiovasc Imaging. 2015;8:1297-305.

19. van Zandvoort LJC, Tomaniak M, Tovar Forero MN, Masdjedi K, Visseren L, Witberg K, Ligthart J, Kardys I, Lemmert ME, Diletti R, Wilschut J, de Jaegere P, Zijlstra F, Van Mieghem NM, Daemen J. Predictors for Clinical Outcome of Untreated Stent Edge Dissections as Detected by Optical Coherence Tomography. Circ Cardiovasc Interv. 2020;13:e008685.

20. Shlofmitz E, Jeremias A, Parviz Y, Karimi Galougahi K, Redfors B, Petrossian G, Edens M, Matsumura M, Maehara A, Mintz GS, Stone GW, Shlofmitz RA, Ali ZA. External elastic lamina vs. luminal diameter measurement for determining stent diameter by optical coherence tomography: an ILUMIEN III substudy. Eur Heart $J$ Cardiovasc Imaging. 2020 Nov 9. [Epub ahead of print].

21. Ali ZA, Maehara A, Généreux P, Shlofmitz RA, Fabbiocchi F, Nazif TM, Guagliumi G, Meraj PM, Alfonso F, Samady H, Akasaka T, Carlson EB, Leesar MA, Matsumura M, Ozan MO, Mintz GS, Ben-Yehuda O, Stone GW; ILUMIEN III: OPTIMIZE PCI Investigators. Optical coherence tomography compared with intravascular ultrasound and with angiography to guide coronary stent implantation (ILUMIEN III: OPTIMIZE PCI): a randomised controlled trial. Lancet. 2016;388:2618-28.

22. Kubo T, Shinke T, Okamura T, Hibi K, Nakazawa G, Morino Y, Shite J, Fusazaki T, Otake H, Kozuma K, Ioji T, Kaneda H, Serikawa T, Kataoka T, Okada H, Akasaka T; OPINION Investigators. Optical frequency domain imaging vs. intravascular 
ultrasound in percutaneous coronary intervention (OPINION trial): one-year angiographic and clinical results. Eur Heart J. 2017;38:3139-47.

23. Mintz GS, Painter JA, Pichard AD, Kent KM, Satler LF, Popma JJ, Chuang YC, Bucher TA, Sokolowicz LE, Leon MB. Atherosclerosis in angiographically "normal" coronary artery reference segments: an intravascular ultrasound study with clinical correlations. J Am Coll Cardiol. 1995;25:1479-85.

24. Koyama K, Fujino A, Maehara A, Yamamoto MH, Alexandru D, Jennings J, Krug P, Santiago LM, Murray M, Bongiovanni L, Lee T, Kim SY, Wang X, Lin Y, Matsumura M, Ali ZA, Sosa F, Haag E, Mintz GS, Shlofmitz RA. A prospective, single-center, randomized study to assess whether automated coregistration of optical coherence tomography with angiography can reduce geographic miss. Catheter Cardiovasc Interv. 2019;93:411-8.

25. Hebsgaard L, Nielsen TM, Tu S, Krusell LR, Maeng M, Veien KT, Raungaard B, Terkelsen CJ, Kaltoft A, Reiber JH, Lassen JF, Christiansen EH, Holm NR. Co-registration of optical coherence tomography and X-ray angiography in percutaneous coronary intervention. the Does Optical Coherence Tomography Optimize Revascularization (DOCTOR) fusion study. Int J Cardiol. 2015;182:272-8.

26. Leistner DM, Riedel M, Steinbeck L, Stähli BE, Fröhlich GM, Lauten A, Skurk C, Mochmann HC, Lübking L, Rauch-Kröhnert U, Schnabel RB, Westermann D, Blankenberg S, Landmesser U. Real-time optical coherence tomography coregistration with angiography in percutaneous coronary intervention-impact on physician decisionmaking: The OPTICO-integration study. Catheter Cardiovasc Interv. 2018;92:30-7.

27. Schneider VS, Böhm F, Blum K, Riedel M, Abdelwahed YS, Klotsche J, Steiner JK, Heuberger A, Skurk C, Mochmann HC, Lauten A, Fröhlich G, Rauch-Kröhnert U, Haghikia A, Sinning D, Stähli BE, Landmesser U, Leistner DM. Impact of real-time angiographic co-registered optical coherence tomography on percutaneous coronary intervention: the OPTICO-integration II trial. Clin Res Cardiol. 2020;110:249-57.

28. Romagnoli E, Sangiorgi GM, Cosgrave J, Guillet E, Colombo A. Drug-eluting stenting: the case for post-dilation. JACC Cardiovasc Interv. 2008;1:22-31.

29. Shlofmitz E, Sosa F, Goldberg A, Maehara A, Ali ZA, Mintz GS, Moses JW, Stone GW, Shlofmitz RA, Jeremias A. Bifurcation and ostial optical coherence tomography mapping (BOOM) - Case description of a novel bifurcation stent technique. Cardiovasc Revasc Med. 2018;19:47-9.

30. Chamié D, Bezerra HG, Attizzani GF, Yamamoto H, Kanaya T, Stefano GT, Fujino Y, Mehanna E, Wang W, Abdul-Aziz A, Dias M, Simon DI, Costa MA Incidence, predictors, morphological characteristics, and clinical outcomes of stent edge dissections detected by optical coherence tomography. JACC Cardiovasc Interv. 2013;6:800-13.

31. Radu MD, Räber L, Heo J, Gogas BD, Jørgensen E, Kelbæk H, Muramatsu T, Farooq V, Helqvist S, Garcia-Garcia HM, Windecker S, Saunamäki K, Serruys PW. Natural history of optical coherence tomography-detected non-flow-limiting edge dissections following drug-eluting stent implantation. EuroIntervention. 2014;9: 1085-94.

32. Wang B, Mintz GS, Witzenbichler B, Souza CF, Metzger DC, Rinaldi MJ, Duffy PL, Weisz G, Stuckey TD, Brodie BR, Matsumura M, Yamamoto MH, Parvataneni R, Kirtane AJ, Stone GW, Maehara A. Predictors and Long-Term Clinical Impact of Acute Stent Malapposition: An Assessment of Dual Antiplatelet Therapy With Drug-Eluting Stents (ADAPT-DES) Intravascular Ultrasound Substudy. $J$ Am Heart Assoc. 2016;5:e004438.

33. Mintz GS. Why are we so concerned with acute incomplete stent apposition? Eur Heart J Cardiovasc Imaging. 2015;16:110-1.

34. Foin N, Lu S, Ng J, Bulluck H, Hausenloy DJ, Wong PE, Virmani R, Joner M. Stent malapposition and the risk of stent thrombosis: mechanistic insights from an in vitro model. EuroIntervention. 2017;13:e1096-8.

35. Joner M, Finn AV, Farb A, Mont EK, Kolodgie FD, Ladich E, Kutys R, Skorija K, Gold HK, Virmani R. Pathology of drug-eluting stents in humans: delayed healing and late thrombotic risk. J Am Coll Cardiol. 2006;48:193-202.

36. Ozaki Y, Okumura M, Ismail TF, Naruse H, Hattori K, Kan S, Ishikawa M, Kawai T, Takagi Y, Ishii J, Prati F, Serruys PW. The fate of incomplete stent apposition with drug-eluting stents: an optical coherence tomography-based natural history study. Eur Heart J. 2010;31:1470-6.

37. Steinberg DH, Mintz GS, Mandinov L, Yu A, Ellis SG, Grube E, Dawkins KD, Ormiston J, Turco MA, Stone GW, Weissman NJ. Long-term impact of routinely detected early and late incomplete stent apposition: an integrated intravascular ultrasound analysis of the TAXUS IV, V, and VI and TAXUS ATLAS workhorse, long lesion, and direct stent studies. JACC Cardiovasc Interv. 2010;3:486-94.

38. Im E, Kim BK, Ko YG, Shin DH, Kim JS, Choi D, Jang Y, Hong MK. Incidences, predictors, and clinical outcomes of acute and late stent malapposition detected by optical coherence tomography after drug-eluting stent implantation. Circ Cardiovasc Interv. 2014;7:88-96.

39. Guo N, Maehara A, Mintz GS, He Y, Xu K, Wu X, Lansky AJ, Witzenbichler B, Guagliumi G, Brodie B, Kellett MA Jr, Dressler O, Parise H, Mehran R, Stone GW.
Incidence, mechanisms, predictors, and clinical impact of acute and late stent malapposition after primary intervention in patients with acute myocardial infarction: an intravascular ultrasound substudy of the Harmonizing Outcomes with Revascularization and Stents in Acute Myocardial Infarction (HORIZONS-AMI) trial. Circulation. 2010;122:1077-84.

40. Romagnoli E, Gatto L, La Manna A, Burzotta F, Taglieri N, Saia F, Amico F, Marco V, Ramazzotti V, Di Giorgio A, Di Vito L, Boi A, Contarini M, Castriota F, Mintz GS, Prati F. Role of residual acute stent malapposition in percutaneous coronary interventions. Catheter Cardiovasc Interv. 2017;90:566-75.

41. van der Hoeven BL, Liem SS, Dijkstra J, Bergheanu SC, Putter H, Antoni ML, Atsma DE, Bootsma M, Zeppenfeld K, Jukema JW, Schalij MJ. Stent malapposition after sirolimus-eluting and bare-metal stent implantation in patients with ST-segment elevation myocardial infarction: acute and 9-month intravascular ultrasound results of the MISSION! intervention study. JACC Cardiovasc Interv. 2008;1:192-201.

42. Soeda T, Uemura S, Park SJ, Jang Y, Lee S, Cho JM, Kim SJ, Vergallo R, Minami Y, Ong DS, Gao L, Lee H, Zhang S, Yu B, Saito Y, Jang IK. Incidence and Clinical Significance of Poststent Optical Coherence Tomography Findings: One-Year Follow-Up Study From a Multicenter Registry. Circulation. 2015;132:1020-9.

43. Räber L, Mintz GS, Koskinas KC, Johnson TW, Holm NR, Onuma Y, Radu MD, Joner M, Yu B, Jia H, Meneveau N, de la Torre Hernandez JM, Escaned J, Hill J, Prati F, Colombo A, di Mario C, Regar E, Capodanno D, Wijns W, Byrne RA, Guagliumi G; ESC Scientific Document Group. Clinical use of intracoronary imaging. Part 1: guidance and optimization of coronary interventions. An expert consensus document of the European Association of Percutaneous Cardiovascular Interventions. Eur Heart J. 2018;39:3281-300.

44. Choi SY, Maehara A, Cristea E, Witzenbichler B, Guagliumi G, Brodie B, Kellet MA Jr, Dressler O, Lansky AJ, Parise H, Mehran R, Mintz GS, Stone GW. Usefulness of minimum stent cross sectional area as a predictor of angiographic restenosis after primary percutaneous coronary intervention in acute myocardial infarction (from the HORIZONS-AMI Trial IVUS substudy). Am J Cardiol. 2012;109:455-60.

45. Hong SJ, Kim BK, Shin DH, Nam CM, Kim JS, Ko YG, Choi D, Kang TS, Kang WC, Her AY, Kim YH, Hur SH, Hong BK, Kwon H, Jang Y, Hong MK; IVUSXPL Investigators. Effect of Intravascular Ultrasound-Guided vs Angiography-Guided Everolimus-Eluting Stent Implantation: The IVUS-XPL Randomized Clinical Trial. JAMA. 2015;314:2155-63.

46. Kang J, Cho YS, Kim SW, Park JJ, Yoon YE, Oh IY, Yoon CH, Suh JW, Youn TJ, Chae IH, Choi DJ. Intravascular Ultrasound and Angiographic Predictors of In-Stent Restenosis of Chronic Total Occlusion Lesions. PLoS One. 2015;10:e 0140421.

47. Kang SJ, Ahn JM, Song H, Kim WJ, Lee JY, Park DW, Yun SC, Lee SW, Kim YH, Lee CW, Mintz GS, Park SW, Park SJ. Comprehensive intravascular ultrasound assessment of stent area and its impact on restenosis and adverse cardiac events in 403 patients with unprotected left main disease. Circ Cardiovasc Interv. 2011;4:562-9.

48. Song HG, Kang SJ, Ahn JM, Kim WJ, Lee JY, Park DW, Lee SW, Kim YH, Lee CW, Park SW, Park SJ. Intravascular ultrasound assessment of optimal stent area to prevent in-stent restenosis after zotarolimus-, everolimus-, and sirolimus-eluting stent implantation. Catheter Cardiovasc Interv. 2014;83:873-8.

49. Lee SY, Shin DH, Kim JS, Kim BK, Ko YG, Choi D, Jang Y, Hong MK. Intravascular Ultrasound Predictors of Major Adverse Cardiovascular Events After Implantation of Everolimus-eluting Stents for Long Coronary Lesions. Rev Esp Cardiol (Engl Ed). 2017;70:88-95.

50. Katagiri Y, De Maria GL, Kogame N, Chichareon P, Takahashi K, Chang CC, Modolo R, Walsh S, Sabate M, Davies J, Lesiak M, Moreno R, Cruz-Gonzalez I, West NEJ, Piek JJ, Wykrzykowska JJ, Farooq V, Escaned J, Banning AP, Onuma Y, Serruys PW. Impact of post-procedural minimal stent area on 2-year clinical outcomes in the SYNTAX II trial. Catheter Cardiovasc Interv. 2019;93:E225-34.

51. Parodi G, Maehara A, Giuliani G, Kubo T, Mintz GS, Migliorini A, Valenti R, Carrabba N, Antoniucci D. Optical coherence tomography in unprotected left main coronary artery stenting. EuroIntervention. 2010;6:94-9.

52. Hu S, Zhu Y, Zhang Y, Dai J, Li L, Dauerman H, Soeda T, Wang Z, Lee H, Wang C, Zhe C, Wang Y, Zheng G, Zhang S, Jia H, Yu B, Jang IK. Management and Outcome of Patients With Acute Coronary Syndrome Caused by Plaque Rupture Versus Plaque Erosion: An Intravascular Optical Coherence Tomography Study. J Am Heart Assoc 2017;6:e004730.

53. Tearney GJ, Regar E, Akasaka T, Adriaenssens T, Barlis P, Bezerra HG, Bouma B, Bruining N, Cho JM, Chowdhary S, Costa MA, de Silva R, Dijkstra J, Di Mario C, Dudek D, Falk E, Feldman MD, Fitzgerald P, Garcia-Garcia HM, Gonzalo N, Granada JF, Guagliumi G, Holm NR, Honda Y, Ikeno F, Kawasaki M, Kochman J, Koltowski L, Kubo T, Kume T, Kyono H, Lam CC, Lamouche G, Lee DP, Leon MB, Maehara A, Manfrini O, Mintz GS, Mizuno K, Morel MA, Nadkarni S, Okura H, Otake H, Pietrasik A, Prati F, Raber L, Radu MD, Rieber J, Riga M, Rollins A, Rosenberg M, Sirbu V, Serruys PW, Shimada K, Shinke T, Shite J, Siegel E, Sonoda S, Suter M, Takarada S, Tanaka A, Terashima M, Thim T, Uemura S, Ughi GJ, van Beusekom HM, van der Steen AF, van Es GA, van Soest G, Virmani R, Waxman S, 
Weissman NJ, Weisz G; International Working Group for Intravascular Optical Coherence Tomography (IWG-IVOCT). Consensus standards for acquisition, measurement, and reporting of intravascular optical coherence tomography studies: a report from the International Working Group for Intravascular Optical Coherence Tomography Standardization and Validation. J Am Coll Cardiol. 2012;59:1058-72.

54. Koh AS, Chia S. Update on clinical imaging of coronary plaque in acute coronary syndrome. Ann Acad Med Singap. 2010;39:203-9.

55. Virmani R, Kolodgie FD, Burke AP, Farb A, Schwartz SM. Lessons from sudden coronary death: a comprehensive morphological classification scheme for atherosclerotic lesions. Arterioscler Thromb Vasc Biol. 2000;20:1262-75.

56. Jia H, Abtahian F, Aguirre AD, Lee S, Chia S, Lowe H, Kato K, Yonetsu T, Vergallo R, Hu S, Tian J, Lee H, Park SJ, Jang YS, Raffel OC, Mizuno K, Uemura S, Itoh T, Kakuta T, Choi SY, Dauerman HL, Prasad A, Toma C, McNulty I, Zhang S, Yu B, Fuster V, Narula J, Virmani R, Jang IK. In vivo diagnosis of plaque erosion and calcified nodule in patients with acute coronary syndrome by intravascular optical coherence tomography. J Am Coll Cardiol. 2013;62:1748-58.

57. Xing L, Yamamoto E, Sugiyama T, Jia H, Ma L, Hu S, Wang C, Zhu Y, Li L, Xu M, Liu H, Bryniarski K, Hou J, Zhang S, Lee H, Yu B, Jang IK. EROSION Study (Effective Anti-Thrombotic Therapy Without Stenting: Intravascular Optical Coherence Tomography-Based Management in Plaque Erosion): A 1-Year Follow-Up Report. Circ Cardiovasc Interv. 2017;10:e005860.

58. Jinnouchi H, Virmani R, Finn AV. Are characteristics of plaque erosion defined by optical coherence tomography similar to true erosion in pathology? Eur Heart $J$. 2018;39:2086-9

59. Duissaillant GR, Mintz GS, Pichard AD, Kent KM, Satler LF, Popma JJ, Griffin J, Leon MB. Intravascular ultrasound identification of calcified intraluminal lesions misdiagnosed as thrombi by coronary angiography. Am Heart J. 1996;132:687-9.

60. Sugiyama T, Yamamoto E, Fracassi F, Lee H, Yonetsu T, Kakuta T, Soeda T, Saito Y, Yan BP, Kurihara O, Takano M, Niccoli G, Crea F, Higuma T, Kimura S, Minami Y, Ako J, Adriaenssens T, Boeder NF, Nef HM, Fujimoto JG, Fuster V, Finn AV, Falk E, Jang IK. Calcified Plaques in Patients With Acute Coronary Syndromes. JACC Cardiovasc Interv. 2019;12:531-40.

61. Prati F, Gatto L, Fabbiocchi F, Vergallo R, Paoletti G, Ruscica G, Marco V, Romagnoli E, Boi A, Fineschi M, Calligaris G, Tamburino C, Crea F, Ozaki Y, Alfonso F, Arbustini E. Clinical outcomes of calcified nodules detected by optical coherence tomography: a sub-analysis of the CLIMA study. EuroIntervention. 2020;16:380-6.

62. Lee T, Mintz GS, Matsumura M, Zhang W, Cao Y, Usui E, Kanaji Y, Murai T, Yonetsu T, Kakuta T, Maehara A. Prevalence, Predictors, and Clinical Presentation of a Calcified Nodule as Assessed by Optical Coherence Tomography. JACC Cardiovasc Imaging. 2017;10:883-91.

63. Reynolds HR, Maehara A, Kwong RY, Sedlak T, Saw J, Smilowitz NR, Mahmud E, Wei J, Marzo K, Matsumura M, Seno A, Hausvater A, Giesler C, Jhalani N, Toma C, Har B, Thomas D, Mehta LS, Trost J, Mehta PK, Ahmed B, Bainey KR, Xia Y, Shah B, Attubato M, Bangalore S, Razzouk L, Ali ZA, Bairey-Merz CN, Park K, Hada E, Zhong H, Hochman JS. Coronary Optical Coherence Tomography and Cardiac Magnetic Resonance Imaging to Determine Underlying Causes of Myocardial Infarction With Nonobstructive Coronary Arteries in Women. Circulation. 2021;143: $624-40$.

64. Kerensky RA, Wade M, Deedwania P, Boden WE, Pepine CJ; Veterans Affairs Non-Q-Wave Infarction Stategies in-Hospital (VANQWISH) Trial Investigators. Revisiting the culprit lesion in non-Q-wave myocardial infarction. Results from the VANQWISH trial angiographic core laboratory. $J$ Am Coll Cardiol. 2002;39:1456-63. 65. Larsen AI, Nilsen DW, Yu J, Mehran R, Nikolsky E, Lansky AJ, Caixeta A, Parise H, Fahy M, Cristea E, Witzenbichler B, Guagliumi G, Peruga JZ, Brodie BR, Dudek D, Stone GW. Long-term prognosis of patients presenting with ST-segment elevation myocardial infarction with no significant coronary artery disease (from the HORIZONS-AMI trial). Am J Cardiol. 2013;111:643-8.

66. Vergallo R, Porto I, D'Amario D, Annibali G, Galli M, Benenati S, Bendandi F, Migliaro S, Fracassi F, Aurigemma C, Leone AM, Buffon A, Burzotta F, Trani C, Niccoli G, Liuzzo G, Prati F, Fuster V, Jang IK, Crea F. Coronary Atherosclerotic Phenotype and Plaque Healing in Patients With Recurrent Acute Coronary Syndromes Compared With Patients With Long-term Clinical Stability: An In Vivo Optical Coherence Tomography Study. JAMA Cardiol. 2019;4:321-9.

67. Fracassi F, Crea F, Sugiyama T, Yamamoto E, Uemura S, Vergallo R, Porto I, Lee H, Fujimoto J, Fuster V, Jang IK. Healed Culprit Plaques in Patients With Acute Coronary Syndromes. J Am Coll Cardiol. 2019;73:2253-63.

68. Russo M, Fracassi F, Kurihara O, Kim HO, Thondapu V, Araki M, Shinohara H, Sugiyama T, Yamamoto E, Lee H, Vergallo R, Crea F, Biasucci LM, Yonetsu T, Minami Y, Soeda T, Fuster V, Jang IK. Healed Plaques in Patients With Stable Angina Pectoris. Arterioscler Thromb Vasc Biol. 2020;40:1587-97.

69. Dai J, Fang C, Zhang S, Li L, Wang Y, Xing L, Yu H, Jiang S, Yin Y, Wang J, Wang Y, Guo J, Lei F, Liu H, Xu M, Ren X, Ma L, Wei G, Zhang S, Hou J, Mintz GS,
Yu B. Frequency, Predictors, Distribution, and Morphological Characteristics of Layered Culprit and Nonculprit Plaques of Patients With Acute Myocardial Infarction: In Vivo 3-Vessel Optical Coherence Tomography Study. Circ Cardiovasc Interv. 2020;13:e009125.

70. Vidal-Perez R, Abou Jokh Casas C, Agra-Bermejo RM, Alvarez-Alvarez B, Grapsa J, Fontes-Carvalho R, Rigueiro Veloso P, Garcia Acuna JM, GonzalezJuanatey JR. Myocardial infarction with non-obstructive coronary arteries: A comprehensive review and future research directions. World J Cardiol. 2019;11:305-15.

71. Stone GW, Maehara A, Lansky AJ, de Bruyne B, Cristea E, Mintz GS, Mehran R, McPherson J, Farhat N, Marso SP, Parise H, Templin B, White R, Zhang Z, Serruys PW, PROSPECT Investigators. A prospective natural-history study of coronary atherosclerosis. N Engl J Med. 2011;364:226-35.

72. Calvert PA, Obaid DR, O'Sullivan M, Shapiro LM, McNab D, Densem CG, Schofield PM, Braganza D, Clarke SC, Ray KK, West NE, Bennett MR. Association between IVUS findings and adverse outcomes in patients with coronary artery disease: the VIVA (VH-IVUS in Vulnerable Atherosclerosis) Study. JACC Cardiovasc Imaging. 2011;4:894-901.

73. Cheng JM, Garcia-Garcia HM, de Boer SP, Kardys I, Heo JH, Akkerhuis KM, Oemrawsingh RM, van Domburg RT, Ligthart J, Witberg KT, Regar E, Serruys PW, van Geuns RJ, Boersma E. In vivo detection of high-risk coronary plaques by radiofrequency intravascular ultrasound and cardiovascular outcome: results of the ATHEROREMO-IVUS study. Eur Heart J. 2014;35:639-47.

74. Erlinge D, Maehara A, Ben-Yehuda O, Bøtker HE, Maeng M, Kjøller-Hansen L, Engstrøm T, Matsumura M, Crowley A, Dressler O, Mintz GS, Fröbert O, Persson J, Wiseth R, Larsen AI, Okkels Jensen L, Nordrehaug JE, Bleie Ø, Omerovic E, Held C, James SK, Ali ZA, Muller JE, Stone GW; PROSPECT II Investigators. Identification of vulnerable plaques and patients by intracoronary near infrared spectroscopy and ultrasound (PROSPECT II): a prospective natural history study. Lancet. 2021;397: 985-95.

75. Stone GW, Maehara A, Ali ZA, Held C, Matsumura M, Kjøller-Hansen L, Bøtker HE, Maeng M, Engstrøm T, Wiseth R, Persson J, Trovik T, Jensen U, James SK, Mintz GS, Dressler O, Crowley A, Ben-Yehuda O, Erlinge D; PROSPECT ABSORB Investigators. Percutaneous Coronary Intervention for Vulnerable Coronary Atherosclerotic Plaque. J Am Coll Cardiol. 2020;76:2289-301.

76. Prati F, Romagnoli E, Gatto L, La Manna A, Burzotta F, Ozaki Y, Marco V, Boi A, Fineschi M, Fabbiocchi F, Taglieri N, Niccoli G, Trani C, Versaci F, Calligaris G, Ruscica G, Di Giorgio A, Vergallo R, Albertucci M, Biondi-Zoccai G, Tamburino C, Crea F, Alfonso F, Arbustini E. Relationship between coronary plaque morphology of the left anterior descending artery and 12 months clinical outcome: the CLIMA study. Eur Heart J. 2020;41:383-91.

77. Xing L, Higuma T, Wang Z, Aguirre AD, Mizuno K, Takano M, Dauerman HL, Park SJ, Jang Y, Kim CJ, Kim SJ, Choi SY, Itoh T, Uemura S, Lowe H, Walters DL, Barlis P, Lee S, Lerman A, Toma C, Tan JWC, Yamamoto E, Bryniarski K, Dai J, Zanchin T, Zhang S, Yu B, Lee H, Fujimoto J, Fuster V, Jang IK. Clinical Significance of Lipid-Rich Plaque Detected by Optical Coherence Tomography: A 4-Year Follow-Up Study. J Am Coll Cardiol. 2017;69:2502-13.

78. Mintz GS. Vulnerable Plaque Detection: When OCT Is Not Enough. JACC Cardiovasc Imaging. 2016;9:173-5.

79. Sinclair H, Bourantas C, Bagnall A, Mintz GS, Kunadian V. OCT for the identification of vulnerable plaque in acute coronary syndrome. JACC Cardiovasc Imaging. 2015;8:198-209.

80. Kim SJ, Lee H, Kato K, Yonetsu T, Xing L, Zhang S, Jang IK. Reproducibility of in vivo measurements for fibrous cap thickness and lipid arc by OCT. JACC Cardiovasc Imaging. 2012;5:1072-4.

81. Phipps JE, Hoyt T, Vela D, Wang T, Michalek JE, Buja LM, Jang IK, Milner TE, Feldman MD. Diagnosis of Thin-Capped Fibroatheromas in Intravascular Optical Coherence Tomography Images: Effects of Light Scattering. Circ Cardiovasc Interv. 2016;9:e003163.

82. Bourantas CV, Jaffer FA, Gijsen FJ, van Soest G, Madden SP, Courtney BK, Fard AM, Tenekecioglu E, Zeng Y, van der Steen AFW, Emelianov S, Muller J, Stone PH, Marcu L, Tearney GJ, Serruys PW. Hybrid intravascular imaging: recent advances, technical considerations, and current applications in the study of plaque pathophysiology. Eur Heart J. 2017;38:400-12.

83. Ughi GJ, Wang H, Gerbaud E, Gardecki JA, Fard AM, Hamidi E, Vacas-Jacques P, Rosenberg M, Jaffer FA, Tearney GJ. Clinical Characterization of Coronary Atherosclerosis With Dual-Modality OCT and Near-Infrared Autofluorescence Imaging. JACC Cardiovasc Imaging. 2016;9:1304-14.

84. Htun NM, Chen YC, Lim B, Schiller T, Maghzal GJ, Huang AL, Elgass KD, Rivera J, Schneider HG, Wood BR, Stocker R, Peter K. Near-infrared autofluorescence induced by intraplaque hemorrhage and heme degradation as marker for high-risk atherosclerotic plaques. Nat Commun. 2017;8:75.

85. Pinilla-Echeverri N, Mehta SR, Wang J, Lavi S, Schampaert E, Cantor WJ, Bainey KR, Welsh RC, Kassam S, Mehran R, Storey RF, Nguyen H, Meeks B, 
Wood DA, Cairns JA, Sheth T. Nonculprit Lesion Plaque Morphology in Patients With ST-Segment-Elevation Myocardial Infarction: Results From the COMPLETE Trial Optical Coherence Tomography Substudys. Circ Cardiovasc Interv. 2020;13:e08768. 86. Hara T, Ughi GJ, McCarthy JR, Erdem SS, Mauskapf A, Lyon SC, Fard AM, Edelman ER, Tearney GJ, Jaffer FA. Intravascular fibrin molecular imaging improves the detection of unhealed stents assessed by optical coherence tomography in vivo. Eur Heart J. 2017;38:447-55.

87. Ali ZA, Galougahi KK, Finn AV. Covering our tracks - optical coherence tomography to assess vascular healing. EuroIntervention. 2018;14:e1247-51.

88. Lutter C, Mori H, Yahagi K, Ladich E, Joner M, Kutys R, Fowler D, Romero M, Narula J, Virmani R, Finn AV. Histopathological Differential Diagnosis of Optical Coherence Tomographic Image Interpretation After Stenting. JACC Cardiovasc Interv. 2016;9:2511-23.

89. Otsuka F, Byrne RA, Yahagi K, Mori H, Ladich E, Fowler DR, Kutys R, Xhepa E, Kastrati A, Virmani R, Joner M. Neoatherosclerosis: overview of histopathologic findings and implications for intravascular imaging assessment. Eur Heart J. 2015; 36:2147-59.

90. Souteyrand G, Amabile N, Mangin L, Chabin X, Meneveau N, Cayla G, Vanzetto G, Barnay P, Trouillet C, Rioufol G, Range G, Teiger E, Delaunay R, Dubreuil O, Lhermusier T, Mulliez A, Levesque S, Belle L, Caussin C, Motreff P; PESTO Investigators. Mechanisms of stent thrombosis analysed by optical coherence tomography: insights from the national PESTO French registry. Eur Heart J. 2016; 37:1208-16.

91. Taniwaki M, Radu MD, Zaugg S, Amabile N, Garcia-Garcia HM, Yamaji K, Jorgensen E, Kelbaek H, Pilgrim T, Caussin C, Zanchin T, Veugeois A, Abildgaard U, Juni P, Cook S, Koskinas KC, Windecker S, Räber L. Mechanisms of Very Late DrugEluting Stent Thrombosis Assessed by Optical Coherence Tomography. Circulation. 2016;133:650-60

92. Jones CR, Khandhar SJ, Ramratnam M, Mulukutla SR, Marroquin OC, Althouse AD, Rao A, Kato K, Jang IK, Toma C. Identification of Intrastent Pathology Associated With Late Stent Thrombosis Using Optical Coherence Tomography. J Interv Cardiol. 2015;28:439-48.

93. Neumann FJ, Sousa-Uva M, Ahlsson A, Alfonso F, Banning AP, Benedetto U, Byrne RA, Collet JP, Falk V, Head SJ, Jüni P, Kastrati A, Koller A, Kristensen SD, Niebauer J, Richter DJ, Seferovic PM, Sibbing D, Stefanini GG, Windecker S, Yadav R, Zembala MO; ESC Scientific Document Group. 2018 ESC/EACTS Guidelines on myocardial revascularization. Eur Heart J. 2019;40:87-165.

94. Witzenbichler B, Maehara A, Weisz G, Neumann FJ, Rinaldi MJ, Metzger DC, Henry TD, Cox DA, Duffy PL, Brodie BR, Stuckey TD, Mazzaferri EL Jr, Xu K, Parise H, Mehran R, Mintz GS, Stone GW. Relationship between intravascular ultrasound guidance and clinical outcomes after drug-eluting stents: the assessment of dual antiplatelet therapy with drug-eluting stents (ADAPT-DES) study. Circulation. 2014;129:463-70.

95. Gao XF, Ge Z, Kong XQ, Kan J, Han L, Lu S, Tian NL, Lin S, Lu QH, Wang XY, Li QH, Liu ZZ, Chen Y, Qian XS, Wang J, Chai DY, Chen CH, Pan T, Ye F, Zhang JJ, Chen SL. Three-year outcomes of the ULTIMATE trial comparing intravascular ultrasound versus angiography-guided drug-eluting stent implantation. JACC Cardiovasc Interv. 2021;14:247-57.

96. Buccheri S, Franchina G, Romano S, Puglisi S, Venuti G, D'Arrigo P, Francaviglia B, Scalia M, Condorelli A, Barbanti M, Capranzano P, Tamburino C, Capodanno D. Clinical Outcomes Following Intravascular Imaging-Guided Versus Coronary Angiography-Guided Percutaneous Coronary Intervention With Stent Implantation: A Systematic Review and Bayesian Network Meta-Analysis of 31 Studies and 17,882 Patients. JACC Cardiovasc Interv. 2017;10:2488-98.

97. Darmoch F, Alraies MC, Al-Khadra Y, Moussa Pacha H, Pinto DS, Osborn EA. Intravascular Ultrasound Imaging-Guided Versus Coronary Angiography-Guided Percutaneous Coronary Intervention: A Systematic Review and Meta-Analysis. J Am Heart Assoc. 2020;9:e013678.

98. Maehara A, Matsumura M, Ali ZA, Mintz GS, Stone GW. IVUS-Guided Versus OCT-Guided Coronary Stent Implantation: A Critical Appraisal. JACC Cardiovasc Imaging. 2017;10:1487-503.

99. Prati F, Di Vito L, Biondi-Zoccai G, Occhipinti M, La Manna A, Tamburino C, Burzotta F, Trani C, Porto I, Ramazzotti V, Imola F, Manzoli A, Materia L, Cremonesi A, Albertucci M. Angiography alone versus angiography plus optical coherence tomography to guide decision-making during percutaneous coronary intervention: the Centro per la Lotta contro l'Infarto-Optimisation of Percutaneous Coronary Intervention (CLI-OPCI) study. EuroIntervention. 2012;8:823-9.

100. Otake H, Kubo T, Takahashi H, Shinke T, Okamura T, Hibi K, Nakazawa G, Morino Y, Shite J, Fusazaki T, Kozuma K, Ioji T, Kaneda H, Akasaka T; OPINION Investigators. Optical Frequency Domain Imaging Versus Intravascular Ultrasound in Percutaneous Coronary Intervention (OPINION Trial): Results From the OPINION Imaging Study. JACC Cardiovasc Imaging. 2018;11:111-23.
101. Habara M, Nasu K, Terashima M, Kaneda H, Yokota D, Ko E, Ito T, Kurita T, Tanaka N, Kimura M, Ito T, Kinoshita Y, Tsuchikane E, Asakura K, Asakura Y, Katoh O, Suzuki T. Impact of frequency-domain optical coherence tomography guidance for optimal coronary stent implantation in comparison with intravascular ultrasound guidance. Circ Cardiovasc Interv. 2012;5:193-201.

102. Ali ZA, Karimi Galougahi K, Maehara A, Shlofmitz RA, Fabbiocchi F, Guagliumi G, Alfonso F, Akasaka T, Matsumura M, Mintz GS, Ben-Yehuda O, Zhang Z, Rapoza RR, West NEJ, Stone GW. Outcomes of optical coherence tomography compared with intravascular ultrasound and with angiography to guide coronary stent implantation: one-year results from the ILUMIEN III: OPTIMIZE PCI trial. EuroIntervention. 2021;16:1085-91.

103. Muramatsu T, Ozaki Y, Nanasato M, Ishikawa M, Nagasaka R, Ohota M, Hashimoto Y, Yoshiki Y, Takatsu H, Ito K, Kamiya H, Yoshida Y, Murohara T, Izawa H; MISTIC-1 Investigators. Comparison Between Optical Frequency Domain Imaging and Intravascular Ultrasound for Percutaneous Coronary Intervention Guidance in Biolimus A9-Eluting Stent Implantation: A Randomized MISTIC-1 Non-Inferiority Trial. Circ Cardiovasc Interv. 2020;13:e009314.

104. Ali Z, Landmesser U, Karimi Galougahi K, Maehara A, Matsumura M, Shlofmitz RA, Guagliumi G, Price MJ, Hill JM, Akasaka T, Prati F, Bezerra HG, Wijns W, Mintz GS, Ben-Yehuda O, McGreevy RJ, Zhang Z, Rapoza RR, West NEJ, Stone GW. Optical coherence tomography guided coronary stent implantation compared to angiography: a multicenter randomized trial in PCI - design and rationale of ILUMIEN IV: OPTIMAL PCI. EuroIntervention. 2021;16:1092-9.

105. Holm NR, Andreasen LN, Walsh S, Kajander OA, Witt N, Eek C, Knaapen P, Koltowski L, Gutiérrez-Chico JL, Burzotta F, Kockman J, Ormiston J, Santos-Pardo I, Laanmets P, Mylotte D, Madsen M, Hjort J, Kumsars I, Råmunddal T, Christiansen EH. Rational and design of the European randomized Optical Coherence Tomography Optimized Bifurcation Event Reduction Trial (OCTOBER). Am Heart J. 2018;205:97-109.

106. Suter MJ, Kashiwagi M, Gallagher KA, Nadkarni SK, Asanani N, Tanaka A, Conditt GB, Tellez A, Milewski K, Kaluza GL, Granada JF, Bouma BE, Tearney GJ. Optimizing flushing parameters in intracoronary optical coherence tomography: an in vivo swine study. Int J Cardiovasc Imaging. 2015;31:1097-106.

107. Ozaki Y, Kitabata H, Tsujioka H, Hosokawa S, Kashiwagi M, Ishibashi K, Komukai K, Tanimoto T, Ino Y, Takarada S, Kubo T, Kimura K, Tanaka A, Hirata K, Mizukoshi M, Imanishi T, Akasaka T. Comparison of contrast media and low-molecular-weight dextran for frequency-domain optical coherence tomography. Circ J. 2012;76:922-7.

108. Vijayvergiya R, Ratheesh KJ, Gupta A. Low molecular weight Dextran: An alternative to radiographic contrast agent for Optical coherence tomography imaging. IHJ Cardiovascular Case Reports. 2017;1:10-11.

109. Hawkins IF. Carbon dioxide digital subtraction arteriography. AJR Am J Roentgenol. 1982;139:19-24.

110. Gore AK, Shlofmitz E, Karimi Galougahi K, Petrossian G, Jeremias A, Sosa FA, Rahim HM, Stone GW, Mintz GS, Maehara A, Shlofmitz RA, Ali ZA. Prospective Comparison Between Saline and Radiocontrast for Intracoronary Imaging With Optical Coherence Tomography. JACC Cardiovasc Imaging. 2020;13:2060-2.

111. Jang SJ, Park HS, Song JW, Kim TS, Cho HS, Kim S, Bouma BE, Kim JW, Oh WY. ECG-Triggered, Single Cardiac Cycle, High-Speed, 3D, Intracoronary OCT. JACC Cardiovasc Imaging. 2016;9:623-5.

112. Iyer JS, Batts SA, Chu KK, Sahin MI, Leung HM, Tearney GJ, Stankovic KM Micro-optical coherence tomography of the mammalian cochlea. Sci Rep. 2016;6: 33288 .

113. Burzotta F, Leone AM, Aurigemma C, Zambrano A, Zimbardo G, Arioti M Vergallo R, De Maria GL, Cerracchio E, Romagnoli E, Trani C, Crea F. Fractional Flow Reserve or Optical Coherence Tomography to Guide Management of Angiographically Intermediate Coronary Stenosis: A Single-Center Trial. JACC Cardiovasc Interv. 2020;13:49-58.

114. Yu W, Huang J, Jia D, Chen S, Raffel OC, Ding D, Tian F, Kan J, Zhang S, Yan F, Chen Y, Bezerra HG, Wijns W, Tu S. Diagnostic accuracy of intracoronary optical coherence tomography-derived fractional flow reserve for assessment of coronary stenosis severity. EuroIntervention. 2019;15:189-97.

115. Im E, Hong SJ, Ahn CM, Kim JS, Kim BK, Ko YG, Choi D, Jang Y, Hong MK. Long-Term Clinical Outcomes of Late Stent Malapposition Detected by Optical Coherence Tomography After Drug-Eluting Stent Implantation. J Am Heart Assoc. 2019;8:e011817.

116. Meneveau N, Souteyrand G, Motreff P, Caussin C, Amabile N, Ohlmann P, Morel O, Lefrancois Y, Descotes-Genon V, Silvain J, Braik N, Chopard R, Chatot M, Ecarnot F, Tauzin H, Van Belle E, Belle L, Schiele F. Optical Coherence Tomography to Optimize Results of Percutaneous Coronary Intervention in Patients with Non-STElevation Acute Coronary Syndrome: Results of the Multicenter, Randomized DOCTORS Study (Does Optical Coherence Tomography Optimize Results of Stenting). Circulation. 2016;134:906-17. 


\section{Supplementary data}

Supplementary Figure 1. Coronary artery spasm.

Supplementary Figure 2. Comparison of calcium fracture by OCT and HD-IVUS.

Supplementary Figure 3. Determination of lesion length on OCT. Supplementary Figure 4. OCT angiographic co-registration.

Supplementary Figure 5. Assessment of stent edge dissection on OCT.

Supplementary Figure 6. Detection of stent edge malapposition by OCT.

Supplementary Figure 7. Assessment of stent expansion on OCT. Supplementary Figure 8. Visualisation of plaque erosion in NSTEMI by OCT.
Supplementary Figure 9. Representative images of calcified plaque morphologies.

Supplementary Figure 10. Representative OCT images demonstrating common types of culprit lesions in MINOCA.

Supplementary Figure 11. Spontaneous coronary artery dissection (SCAD) on OCT.

Supplementary Figure 12. Cross-sectional images of OCT-NIRAF and OCT-NIRS.

Supplementary Figure 13. OCT-guided double-kiss crush stenting of the LAD-D1 bifurcation.

The supplementary data are published online at:

https://eurointervention.pcronline.com/

doi/10.4244/EIJ-D-21-00089 


\section{Supplementary data}

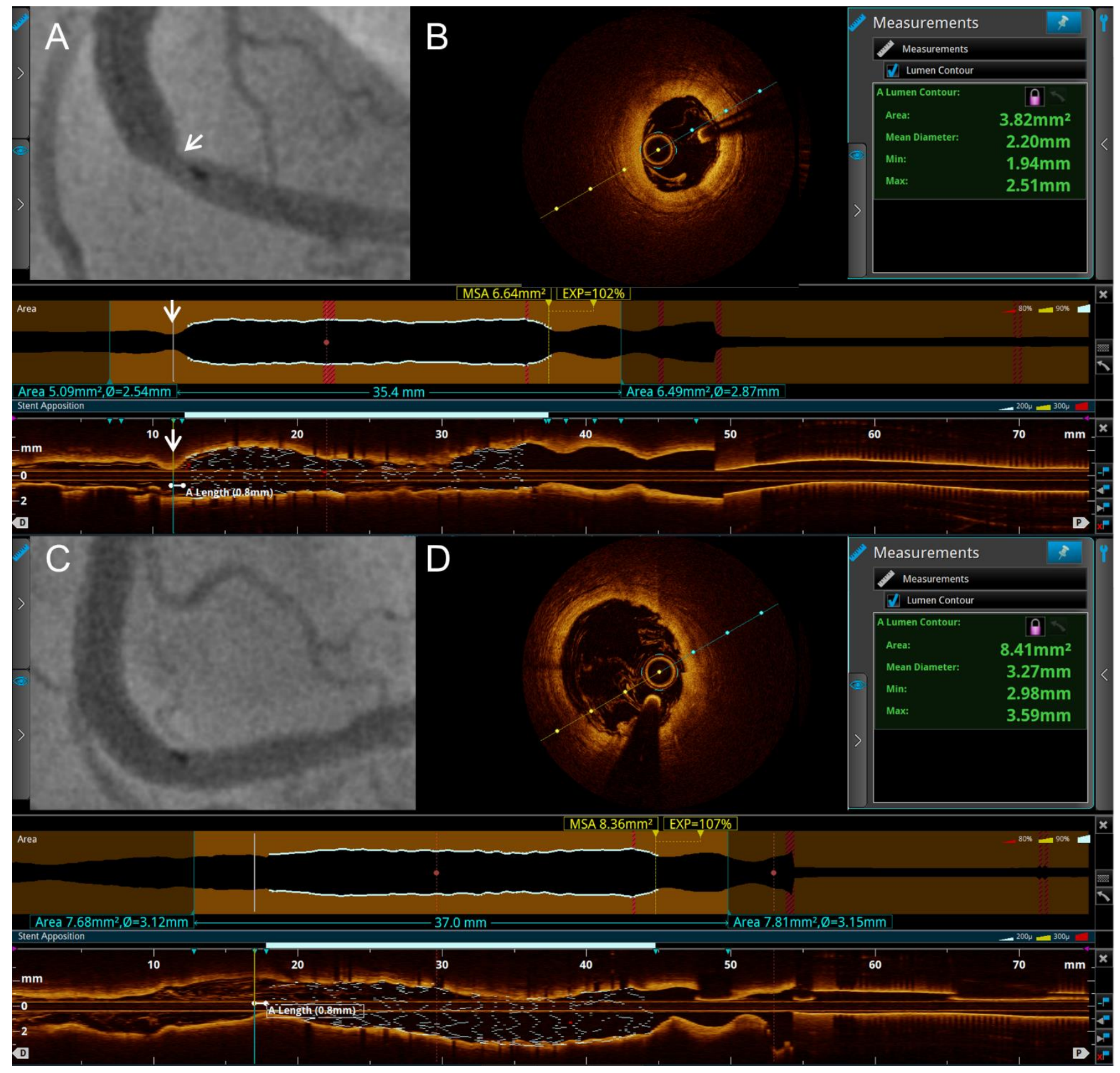

Supplementary Figure 1. Coronary artery spasm.

Following PCI optimisation, angiography (A) and OCT (B) identify severe luminal narrowing (arrowhead) at the distal stent edge with a minimal lumen area of $3.82 \mathrm{~mm}^{2}$. Following administration of $200 \mathrm{mcg}$ of intracoronary nitroglycerine, the luminal narrowing disappeared on angiography (C) and OCT (D) (arrowhead), with an improvement in the luminal area at the site of previous minimal lumen area to $8.41 \mathrm{~mm}^{2}$. 


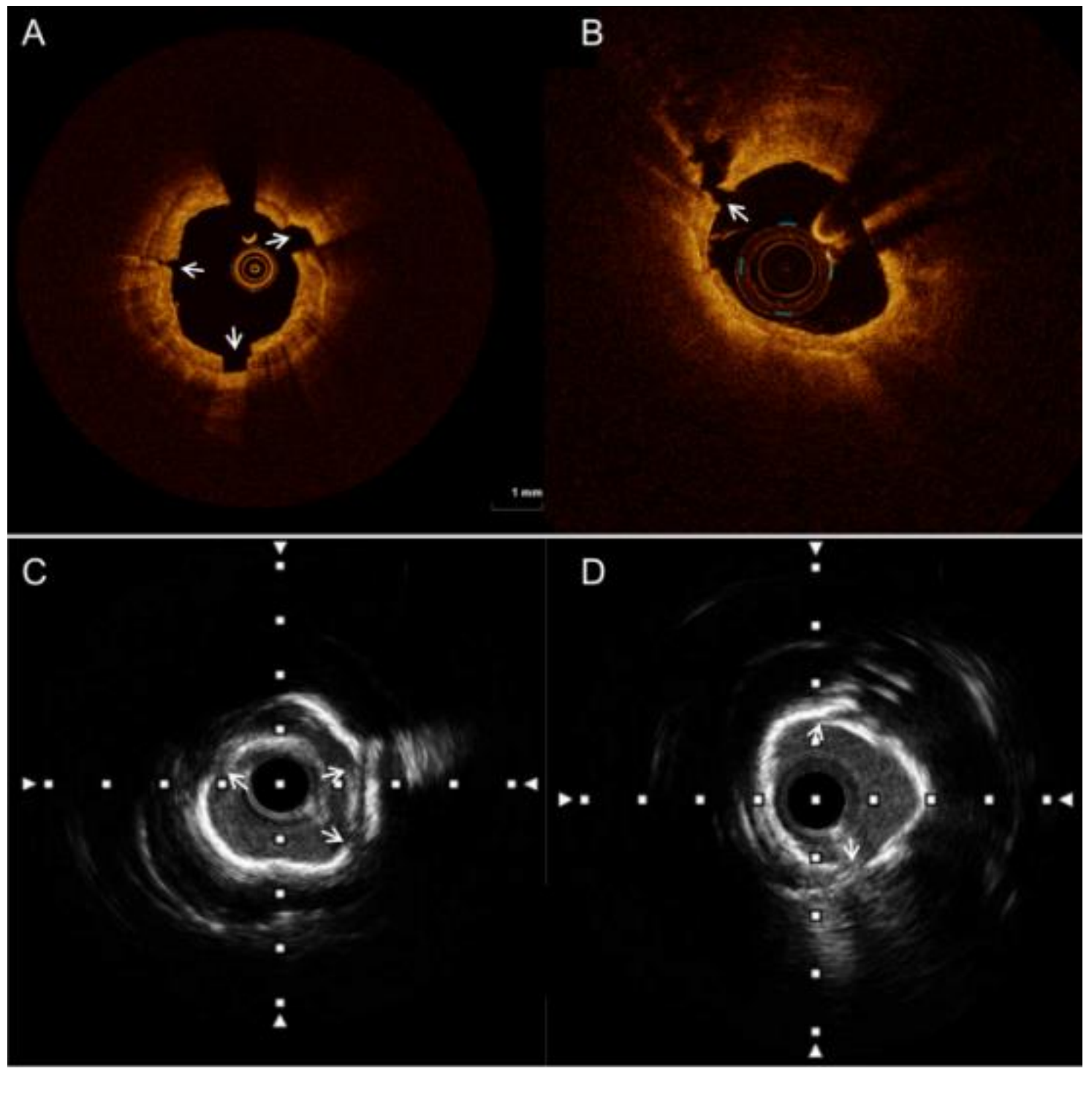

Supplementary Figure 2. Comparison of calcium fracture by OCT and HD-IVUS.

A) \& B) Calcified plaque is visualised with low attenuation and sharply delineated borders on OCT. Arrows show calcium fracture.

C) \& D) Calcified plaque on IVUS is identified as a region having a hyperechoic leading edge with acoustic shadowing. Gaps with reverberation in the hyperechoic region represent calcium fractures (arrows). 


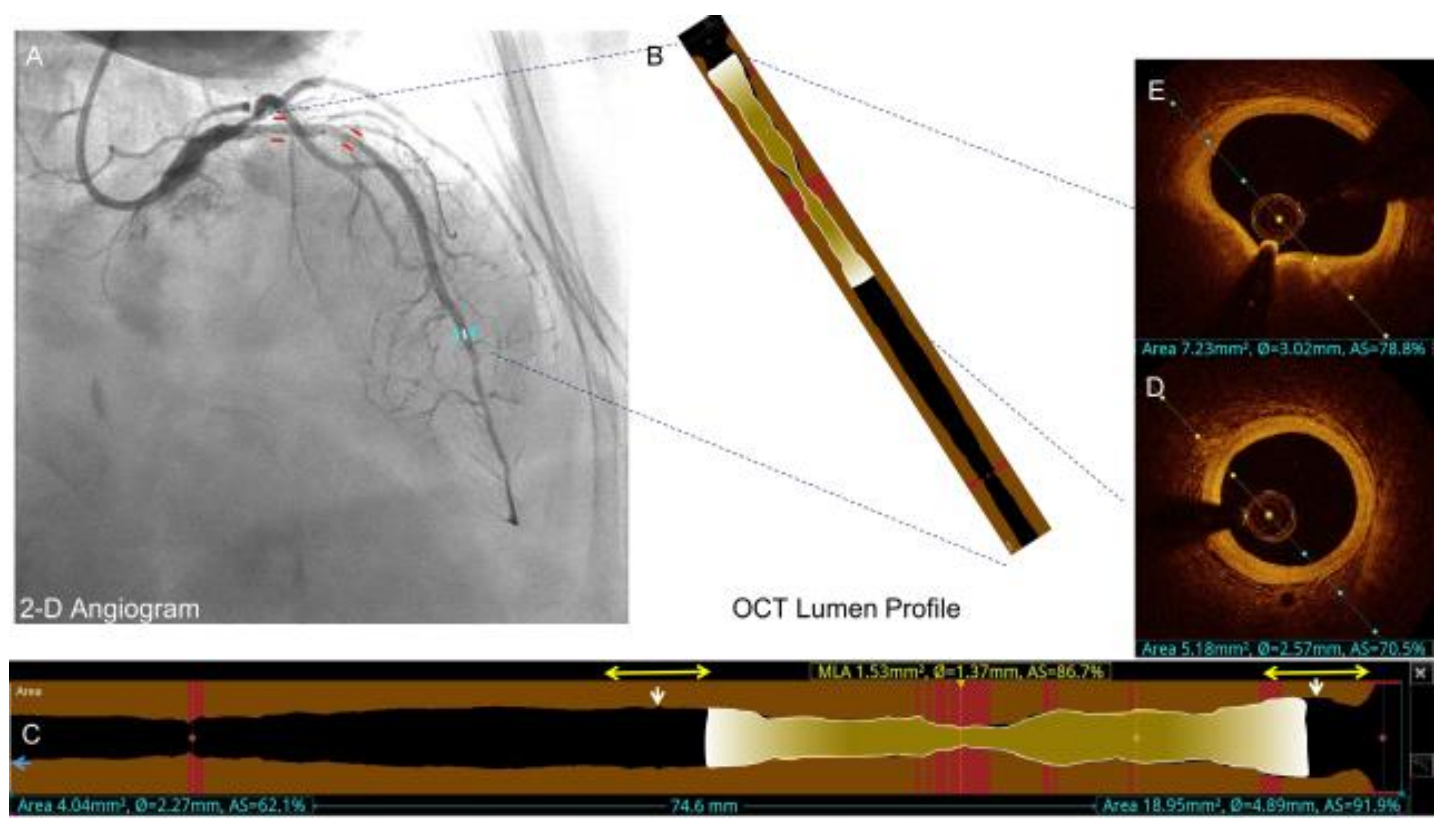

Supplementary Figure 3. Determination of lesion length on OCT.

A) Coronary angiogram represents a 2D image lumenogram of a 3D structure.

B) \& C) The OCT lumen profile accounts for the 3D structure of the coronary artery lumen by incorporating mean diameter measurements as a multiplanar reconstruction. On the lumen profile, the reference vessel markers (blue arrows) are moved to the respective distal and proximal reference crosssections, determined with the largest diameter based on visual estimation of the profile (white arrows). The cross-sections are examined as safe landing zones by assessment of the amount of visible EEL. If 360 degrees of the EEL is not visible, the segments within $5 \mathrm{~mm}$ proximal and distal to the chosen reference frame (yellow arrow) are perused to identify the segment with the maximal visible EEL. Finally, either the proximal or distal reference marker, whichever is on the side with greater EEL visibility, is adjusted to a commercially available DES size. 


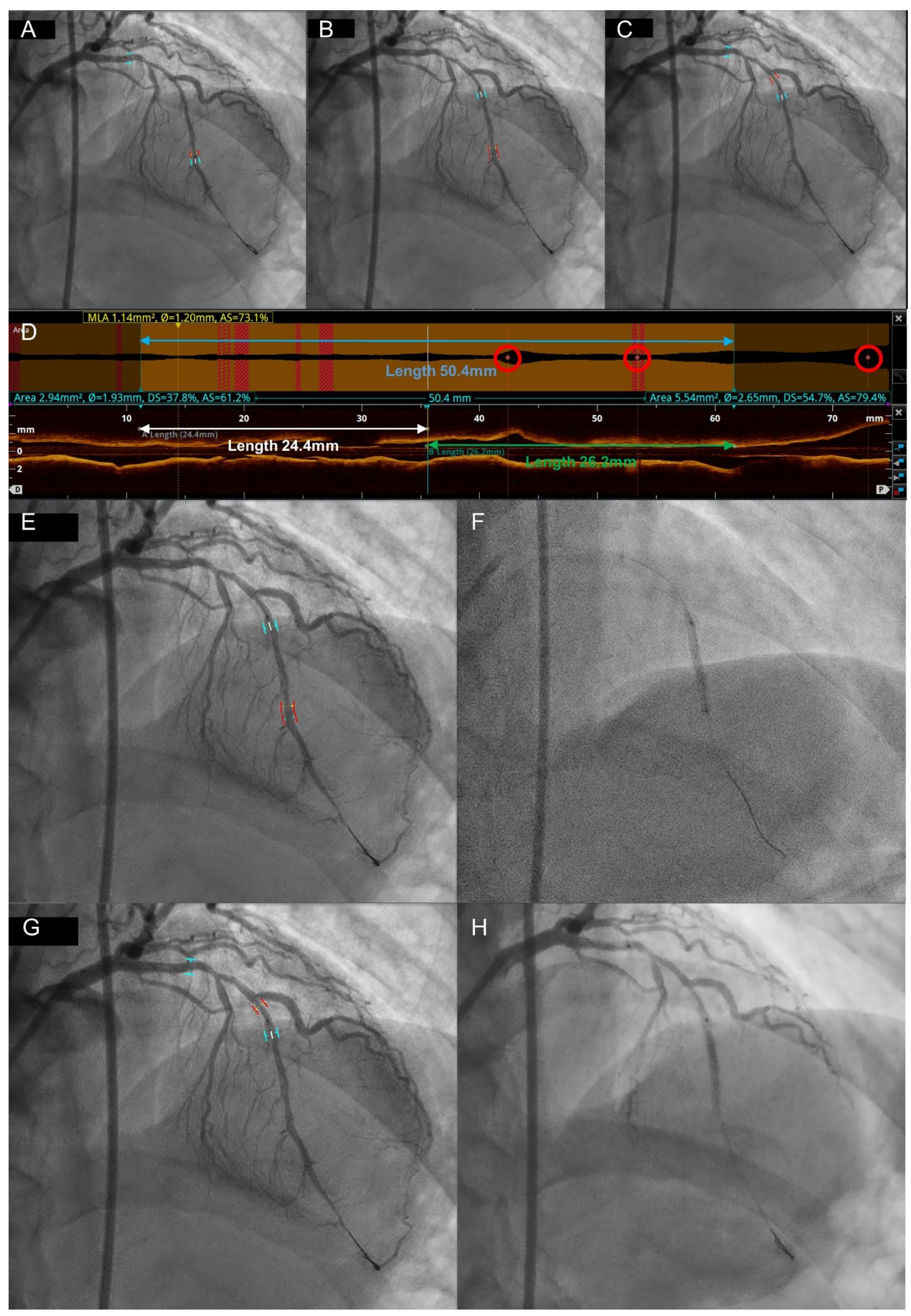


Supplementary Figure 4. OCT angiographic co-registration.

A) OCT angiographic co-registration displays the reference landing zones (blue bars) in a long lesion, highlighting the total, and individual $(\mathrm{B}, \mathrm{C})$ stent lengths required.

D) On OCT lumen profile, the total stent length required is calculated to be $50.4 \mathrm{~mm}$ (blue arrow). The lumen profile also facilitates planning for placement of the distal (white arrow, $24.4 \mathrm{~mm}$ ) and proximal (green arrow, $26.2 \mathrm{~mm}$ ) devices, thus avoiding double jailing of the OCT-detected side branches (red circles).

E) The reference markers are adjusted to guide placement of the distal stent ( $28 \mathrm{~mm})$, by aligning the OCT co-registration mark adjacent to the (F) live fluoroscopy screen.

$\mathrm{G})$ The reference markers are re-adjusted to guide placement of the proximal stent $(28 \mathrm{~mm})$ by aligning the OCT co-registration mark adjacent to the $(\mathrm{H})$ live fluoroscopy screen, confirming overlap of the two stents. 


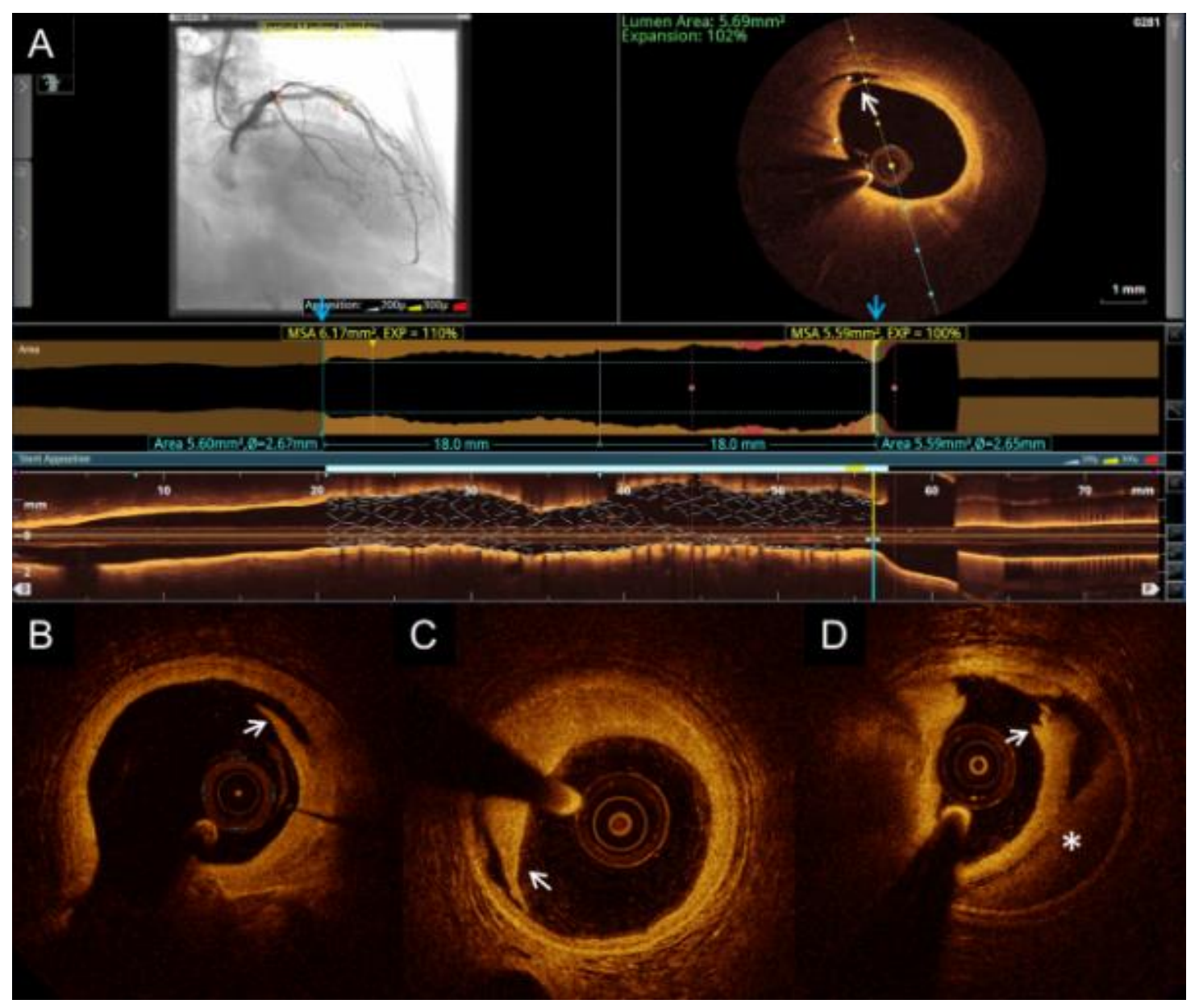

Supplementary Figure 5. Assessment of stent edge dissection on OCT.

A) Identification of the stent edge dissection (white arrow) is facilitated by automated stent rendering, allowing rapid perusal of the stent edges (blue arrows).

B) Dissections confined to the intima are considered benign as progression to intramural haematoma is rare.

C) Dissections penetrating the medial layer may progress to (D) intramural haematoma and therefore should be considered for treatment if deemed major ( $>1$ quadrant in arc), particularly at the distal stent edge where dissection is associated with adverse events. 


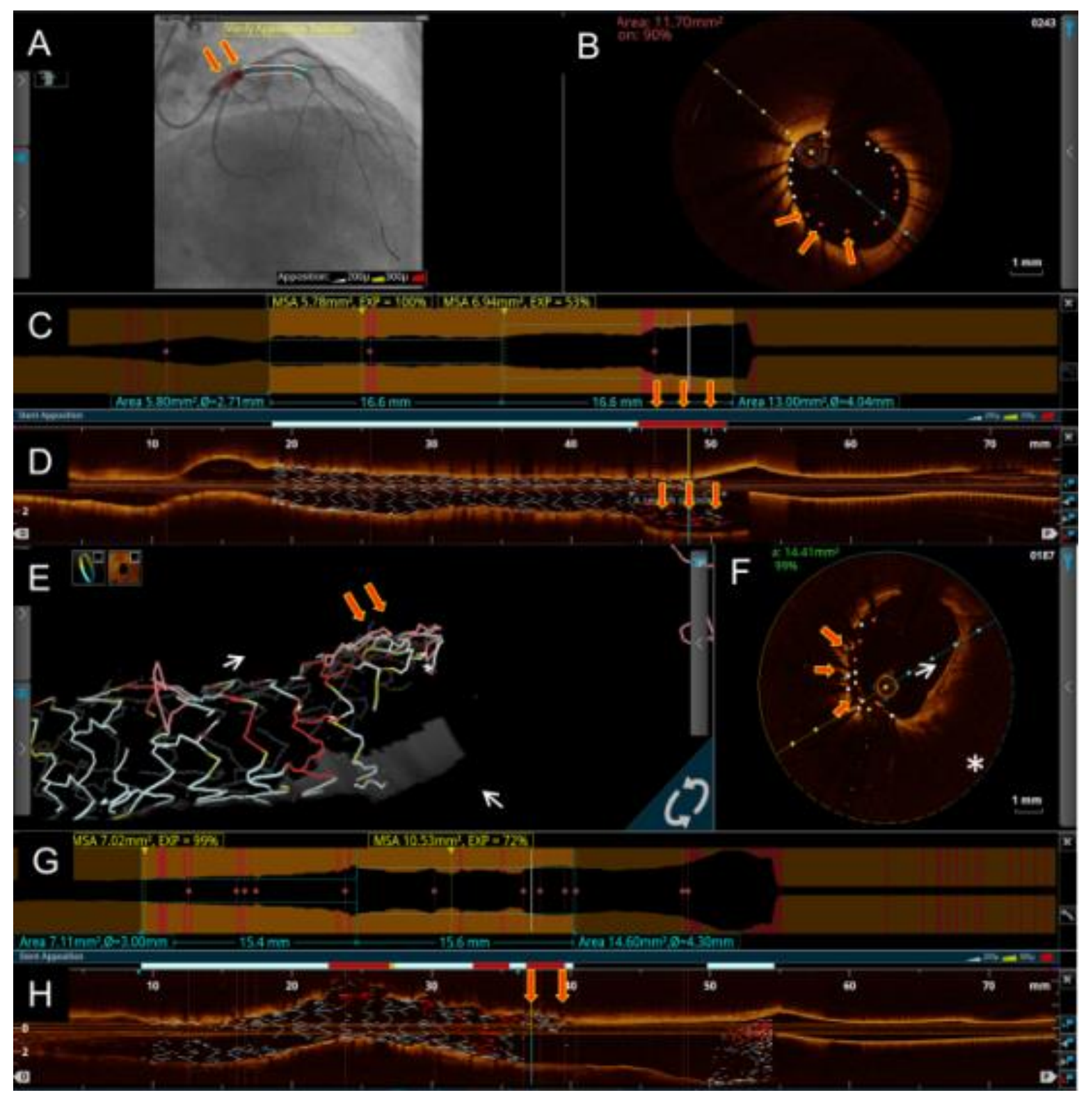

Supplementary Figure 6. Detection of stent edge malapposition by OCT.

A) Automated detection of malapposition on OCT. The high resolution of OCT allows automatic detection of malapposition. Malapposed segments and stent struts are highlighted in red in the angiographic co-registration (B), OCT cross-section (C), automated measures apposition bar (red arrows - red segments of white bar denote malapposed segments) (D) and rendered stent (red arrowheads, red stent struts of white rendered stent denote malapposed segments) on the longitudinal OCT image.

E) 3D stent rendering mode identifies the consequences of wiring through malapposed stent struts followed by balloon dilation leading to stent deformation. Malapposed segments and stent struts are highlighted in red in the 3D mode (F), OCT cross-section $(\mathrm{G})$, automated measures apposition bar (red arrows - red segments of white bar denote malapposed segments) $(\mathrm{H})$ and rendered stent (red arrowheads - red stent struts of white rendered stent denote malapposed segments) on the longitudinal OCT image. 


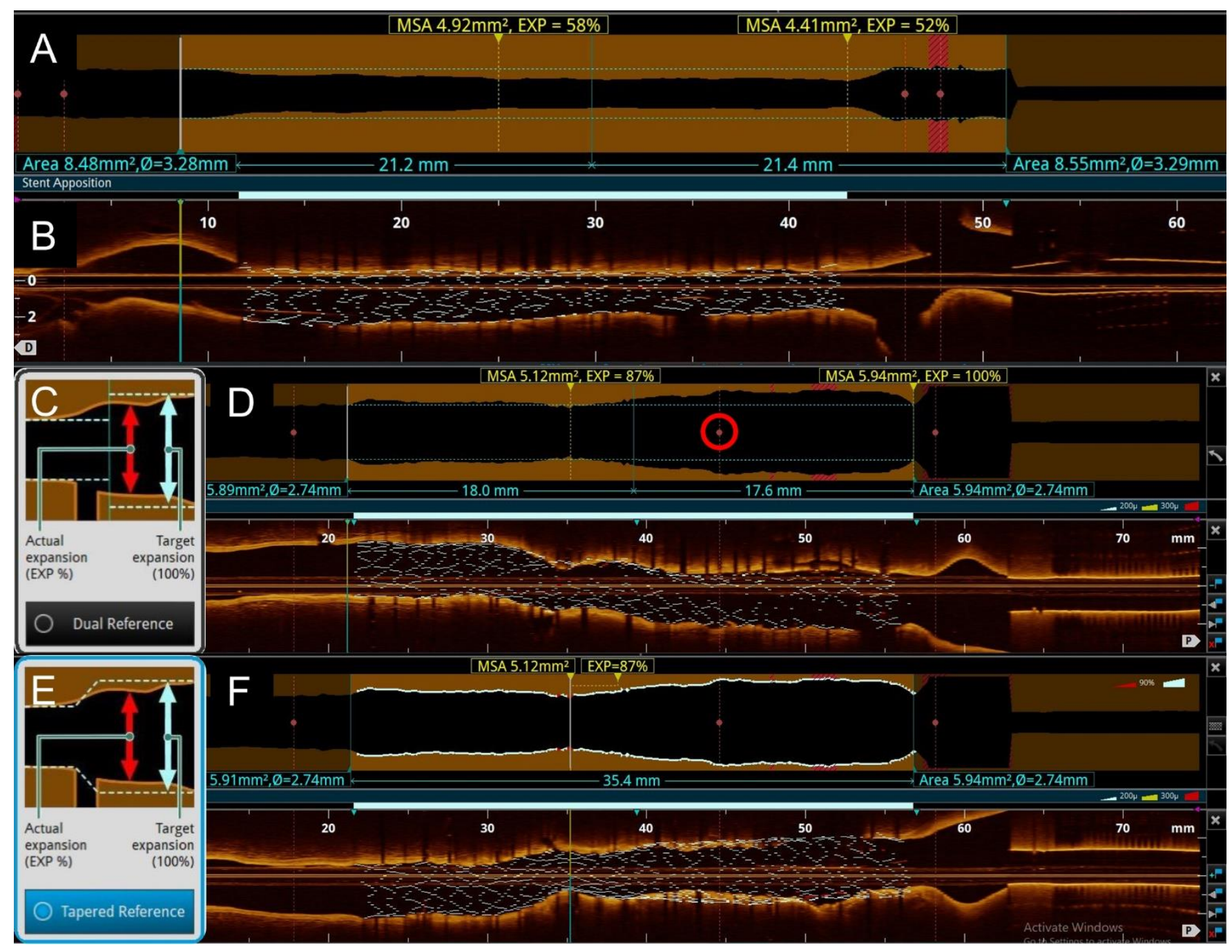

Supplementary Figure 7. Assessment of stent expansion on OCT.

A) The automated lumen profile shows stent expansion of 58\% in the distal half and $52 \%$ in the proximal half of the stent (using the dual reference method). However, there is complete apposition (B) in the longitudinal OCT image (white bar), highlighting the difference between malapposition and expansion.

C) Using the dual reference mode, the stent is automatically split into two halves, (D) automatically showing an $87 \%$ expansion in the distal half, and $100 \%$ expansion in the proximal half. In the presence of a visually estimated $2.5 \mathrm{~mm}$ side branch, the stent should be split into segments, rather than halves, identified by the OCT automated side branch detection (red circle).

E) Using the tapered reference mode, the expansion is calculated based on interpolation of the expected tapering that occurs with side branches, $(\mathrm{F})$ automatically showing an $87 \%$ expansion. Note 
that the expansion in the tapered mode and the dual reference mode are the same, as the side branch had not markedly changed the interpolated reference vessel size.
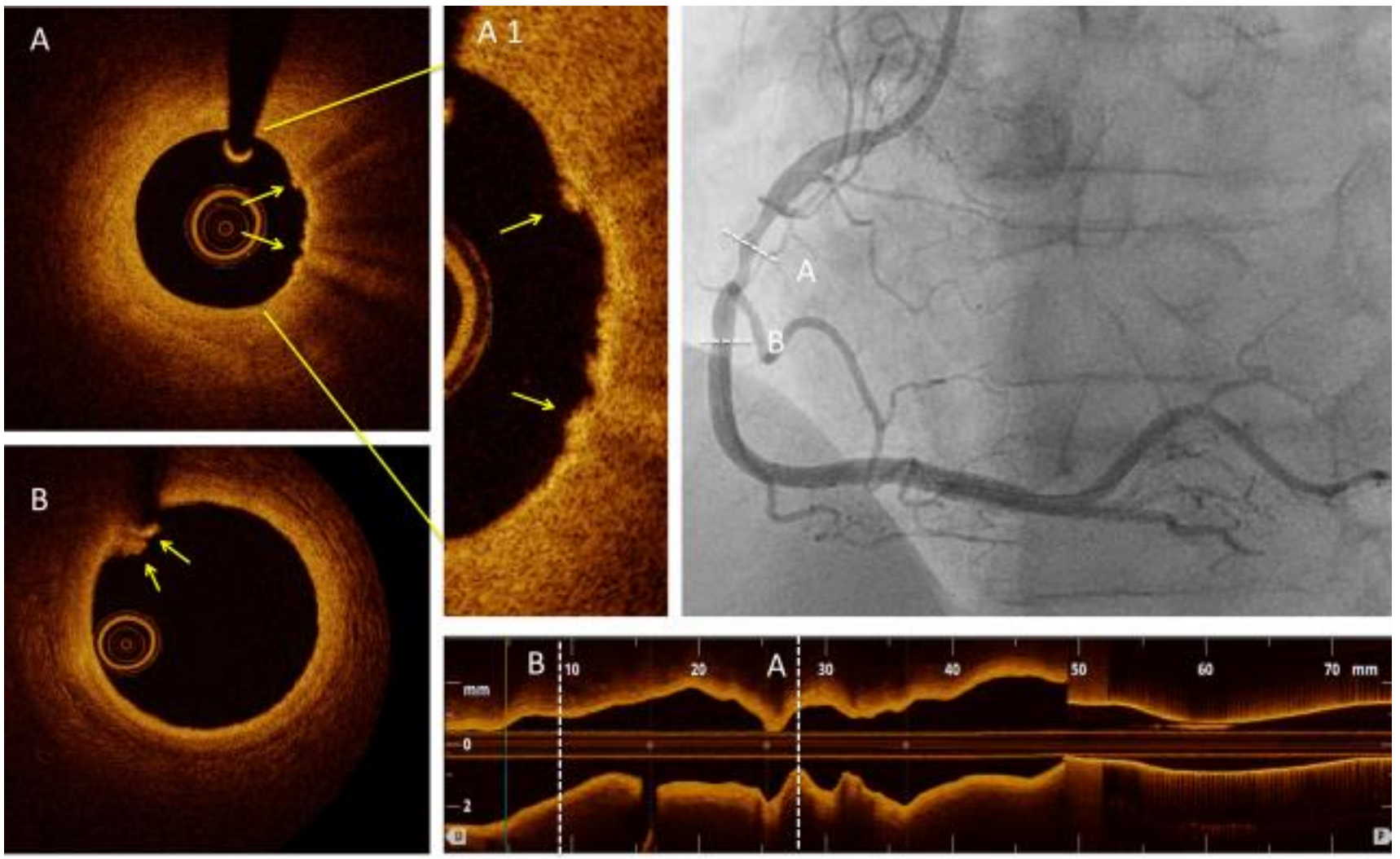

Supplementary Figure 8. Visualisation of plaque erosion in NSTEMI by OCT.

A) OCT of a moderately stenotic mid-RCA lesion identifies (A1) irregular luminal surface, suggestive of endothelial denudation (arrows).

B) OCT identifies residual thrombus in the distal reference section (arrows). 


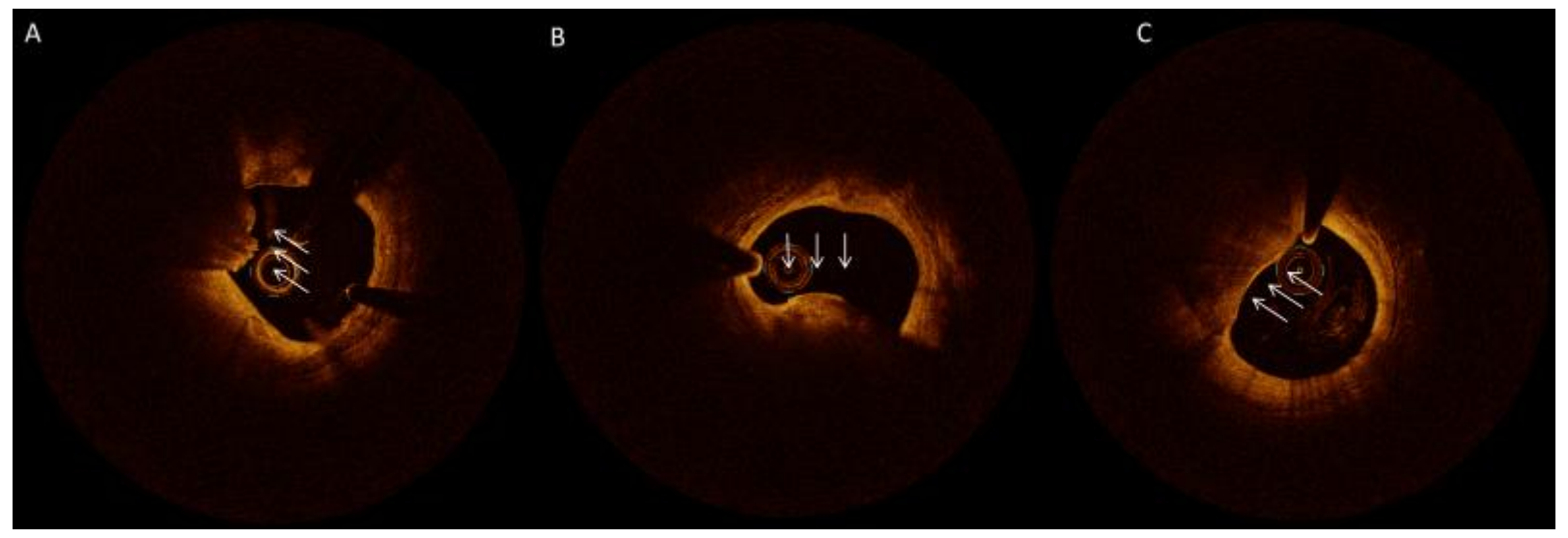

Supplementary Figure 9. Representative images of calcified plaque morphologies.

A) Eruptive calcific nodule is typically identified by a cluster of small calcific nodules protruding into the lumen.

B) Calcified protrusion is identified as a protruding calcific mass without small eruptive calcific nodules.

C) Calcific sheet is identified as sheet-like superficial calcific plate with minimal or no disruption of the overlying fibrous tissue and minimal compromise of the lumen. 
A

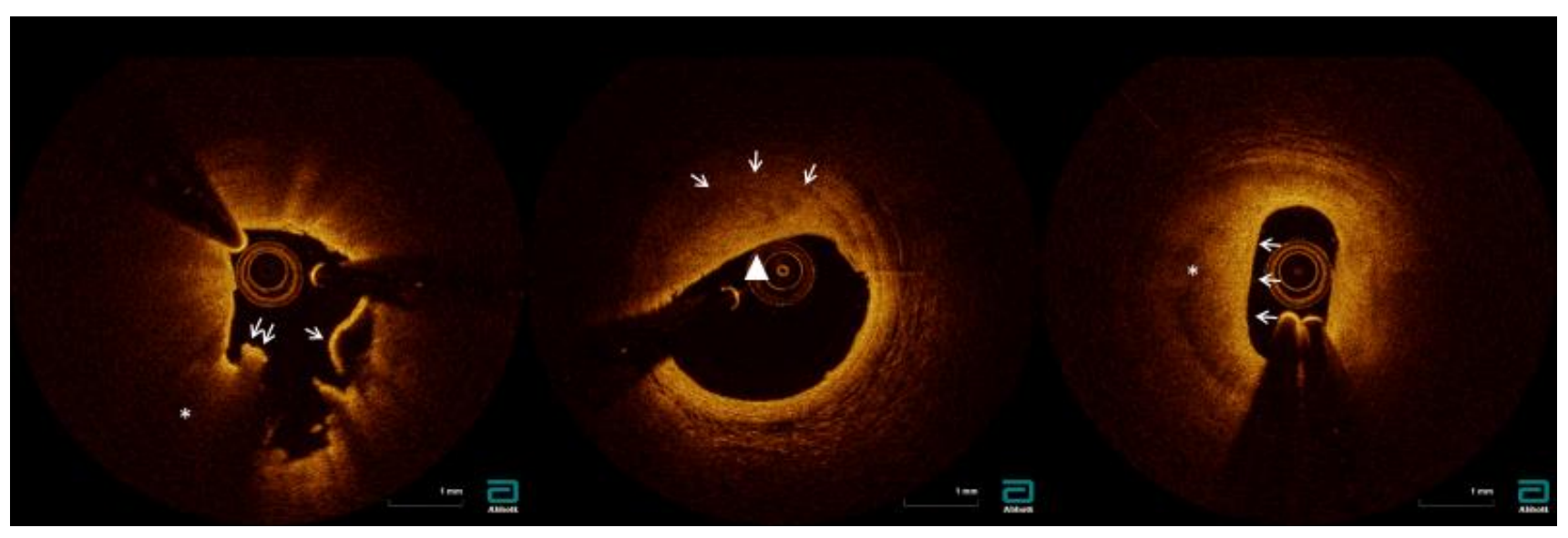

Supplementary Figure 10. Representative OCT images demonstrating common types of culprit lesions in MINOCA.

A) Plaque rupture. There is discontinuity of a thin fibrous cap (arrow), indicating plaque rupture. There is red thrombus adjacent to the rupture site (double arrow). The underlying plaque is a lipidic plaque ${ }^{*}$ ).

B) Intra-plaque cavity. There are low-intensity regions with limited attenuation indicating organised thrombus and/or injected contrast in the ruptured cavity (arrowhead) overlaying a high-backscattered fibrous cap (arrows).

C) Layered plaque. There is a heterogeneous layer (arrows) overlaying a lipidic plaque $(*)$ indicating healing of a recent plaque rupture. 


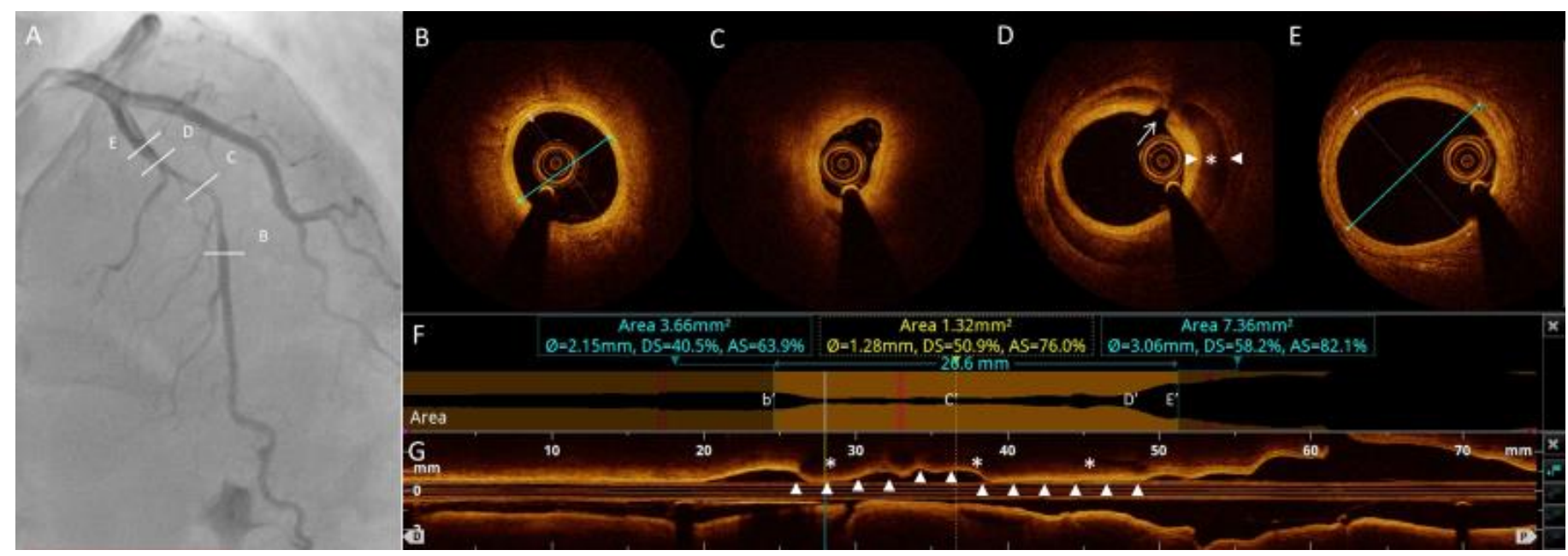

Supplementary Figure 11. Spontaneous coronary artery dissection (SCAD) on OCT.

A) Angiography identifies a luminal narrowing in the mid-LAD artery.

B) - E) OCT cross-sectional images of the distal (B) and proximal (E) segments appear as normal, while intimal disruption (arrow) and intramural haematoma (IMH, asterisk) developed inside a false lumen within the media (arrowheads) are identified (D), causing significant luminal obstruction (C).

F) The length of the dissection and diameter and area stenosis are shown on the automated longitudinal measurements while, on the longitudinal OCT image $(\mathrm{G})$, the length of the affected segments (arrowheads) and extent of the IMH (asterisks) are visualised with reference to cross-sections B-E. 


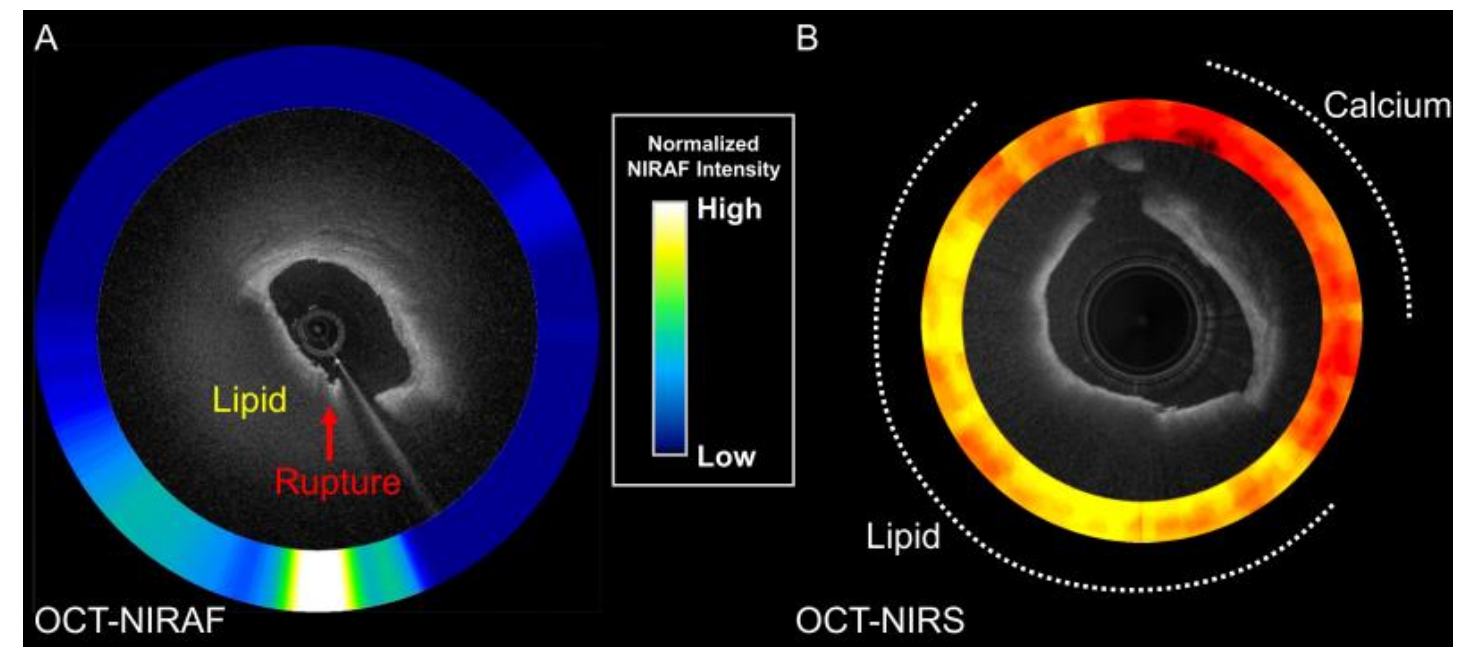

Supplementary Figure 12. Cross-sectional images of (A) OCT-near-infrared autofluorescence (NIRAF), highlighting increased NIRAF signal at the site of a plaque rupture in vivo.

B) OCT-near-infrared spectroscopy (NIRS) in a cadaver specimen, highlighting the ability of NIRS to detect lipid. Courtesy of Gary Tearney, Ali Fard, Farouc Jaffer, Giovanni Ughi. 


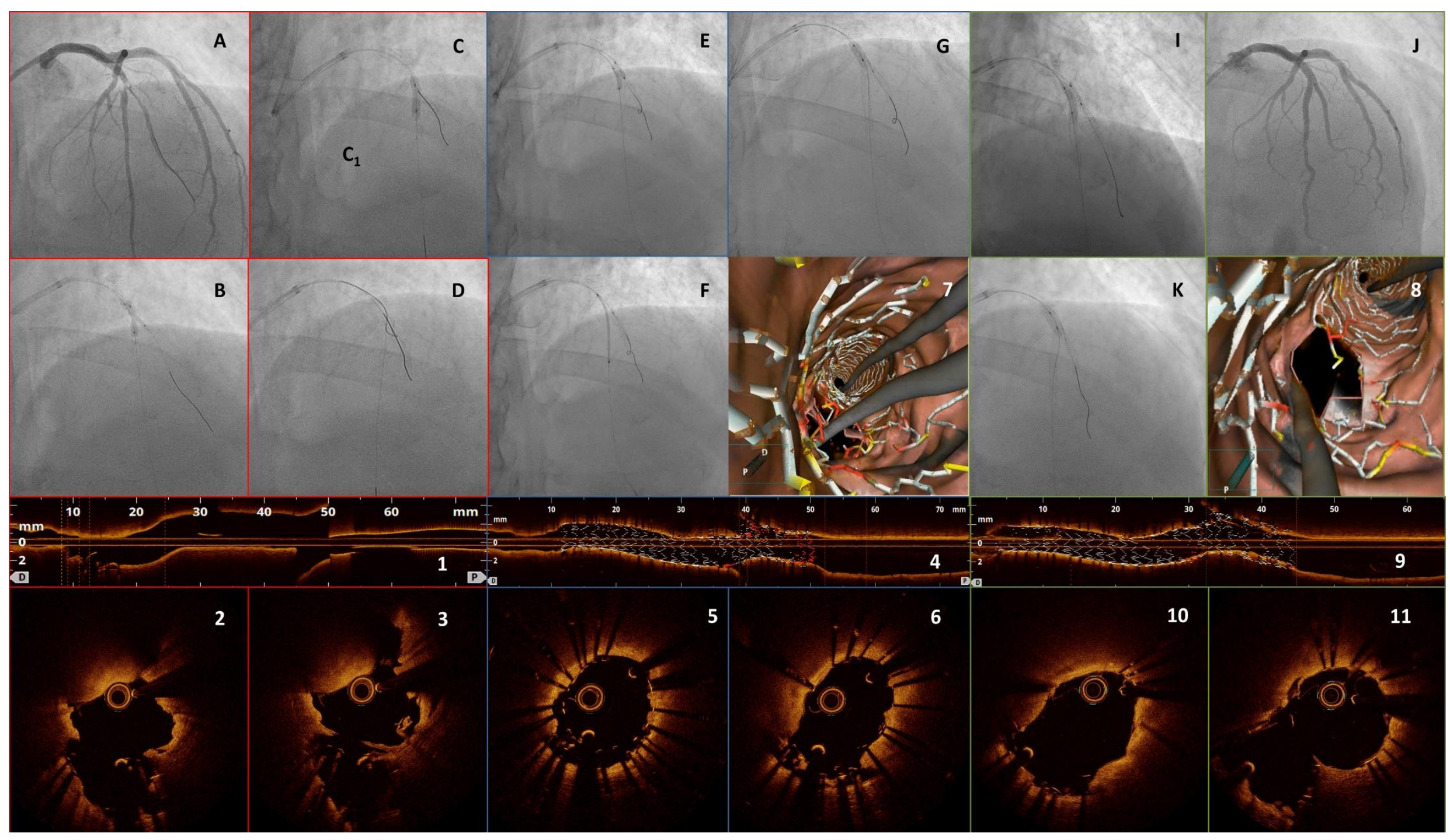


Supplementary Figure 13. OCT-guided double-kiss crush stenting of the LAD-D1 bifurcation.

A) Angiography identifies severe bifurcation disease at the LAD-D1 bifurcation with the angle $<70^{\circ}$.

B) Kissing balloon inflation was used for lesion preparation, followed by $\left(\mathrm{C}_{1}\right)$ positioning of balloon in the main branch (MB) and stent in side branch (SB) and subsequent (C) crushing of the deployed SB stent with main vessel balloon inflation.

D) Rewiring of the SB was performed through the crushed SB stent struts, trying to cross the proximal cell. OCT images: (1) long-axis view of the lesion after SB stenting and rewiring, with cross-sections showing (2) wire crossing the SB stent cells (rhombus) in a proximal position, position of MB guidewire (asterisk) and (3) wire positioned in the SB stent (rhombus). Following the (E) first kissing balloon inflation between stented SB and MB vessel, (F) the MB stent was positioned in the LAD artery and deployed. Subsequently, (G) the first proximal optimisation technique (POT) and second rewiring through struts of the MB stent to the SB were performed. OCT images: (4) long-axis view after MB

stenting and second rewiring with (5) wire distally crossing through MB stent cells (rhombus) and guidewire in the MB stented vessel (asterisk) with (6) wire correctly positioned in the SB stent (rhombus). (7) 3D rendering in bifurcation mode shows the architecture of the stent struts with deformation and covering of the SB ostium.

I) Second kissing balloon inflation between the stented MB and SB with (K) final POT with non-compliant balloon and (J) final angiography. OCT images: (8) 3D bifurcation mode showing opened SB struts without significant malapposition and (9) long axis with rendered stent well apposed. Cross-sections $(10,11)$ show excellent apposition and expansion. 